\title{
Ploidy influences the functional attributes of de novo lager yeast hybrids
}

\author{
Kristoffer Krogerus $^{1,2} \cdot$ Mikko Arvas $^{1} \cdot$ Matteo De Chiara $^{3} \cdot$ Frederico Magalhães $^{1,2}$. \\ Laura Mattinen ${ }^{4}$ - Merja Oja ${ }^{1}$ • Virve Vidgren ${ }^{1}$. Jia-Xing Yue ${ }^{3}$ - Gianni Liti ${ }^{3}$. \\ Brian Gibson ${ }^{1}$
}

Received: 28 January 2016 /Revised: 3 April 2016 / Accepted: 24 April 2016 /Published online: 17 May 2016

(C) The Author(s) 2016. This article is published with open access at Springerlink.com

\begin{abstract}
The genomes of hybrid organisms, such as lager yeast (Saccharomyces cerevisiae $\times$ Saccharomyces eubayanus), contain orthologous genes, the functionality and effect of which may differ depending on their origin and copy number. How the parental subgenomes in lager yeast contribute to important phenotypic traits such as fermentation performance, aroma production, and stress tolerance remains poorly understood. Here, three de novo lager yeast hybrids with different ploidy levels (allodiploid, allotriploid, and allotetraploid) were generated through hybridization techniques without genetic modification. The hybrids were characterized in fermentations of both high gravity wort $\left(15^{\circ} \mathrm{P}\right)$ and very high gravity wort $\left(25^{\circ} \mathrm{P}\right)$, which were monitored for aroma compound and sugar concentrations. The hybrid strains with higher DNA content performed better during fermentation and produced higher concentrations of flavor-active esters in both worts. The hybrid strains also outperformed both the parent strains. Genome sequencing revealed that several genes
\end{abstract}

Electronic supplementary material The online version of this article (doi:10.1007/s00253-016-7588-3) contains supplementary material, which is available to authorized users.

Kristoffer Krogerus

kristoffer.krogerus@aalto.fi

1 VTT Technical Research Centre of Finland, Tietotie 2, P.O. Box 1000, FI-02044 Espoo, Finland

2 Department of Biotechnology and Chemical Technology, Aalto University, School of Chemical Technology, Kemistintie 1, Aalto, P.O. Box 16100, FI-00076 Espoo, Finland

3 Institute for Research on Cancer and Ageing of Nice (IRCAN), CNRS UMR 7284, INSERM U1081, University of Nice Sophia Antipolis, 06107 Nice, France

4 ValiRx Finland Oy, Kiviharjuntie 8, FI-90220 Oulu, Finland related to the formation of flavor-active esters (ATF1, ATF2, $E H T 1, E E B 1$, and $B A T 1$ ) were present in higher copy numbers in the higher ploidy hybrid strains. A direct relationship between gene copy number and transcript level was also observed. The measured ester concentrations and transcript levels also suggest that the functionality of the $S$. cerevisiaeand $S$. eubayanus-derived gene products differs. The results contribute to our understanding of the complex molecular mechanisms that determine phenotypes in lager yeast hybrids and are expected to facilitate targeted strain development through interspecific hybridization.

Keywords Lager yeast $\cdot$ S. eubayanus $\cdot$ Brewing $\cdot$ Hybrid . Rare mating $\cdot$ Heterosis

\section{Introduction}

Interspecific hybridization has shown great potential as a strain development tool for the brewing industry, where the natural hybrid yeast Saccharomyces pastorianus is utilized to produce the majority of beer worldwide (Gibson and Liti 2015; Hebly et al. 2015; Krogerus et al. 2015a; Mertens et al. 2015). Hybrid species tend to exhibit superior phenotypic qualities compared to one or both parents, i.e., heterosis or hybrid vigor, and this has also been observed in yeast hybrids, which can exhibit improved fermentation rates, greater stress tolerance, and increases in aroma compound production (Bellon et al. 2011; Chen 2013; Gamero et al. 2013; Hebly et al. 2015; Krogerus et al. 2015a; Mertens et al. 2015; Plech et al. 2014; Snoek et al. 2015; Steensels et al. 2014a). Previous studies (Krogerus et al. 2015a; Mertens et al. 2015) reveal that de novo lager yeast hybrids can outperform their parent strains during fermentation and produce beer with similar or higher 
concentrations of aroma compounds compared to beers produced with the parent strains.

The molecular mechanisms responsible for heterosis are complex and not fully understood. Traditionally, attempts have been made to explain heterosis with the "dominance" and "overdominance" hypotheses, but recent findings using "omics" approaches have suggested more complex mechanisms: allelic interactions, transcriptional regulation, and epigenetic regulation (Chen 2013; Fu et al. 2015; Lippman and Zamir 2007; Shapira et al. 2014). During interspecific hybridization, alloploidization occurs, and allelic genes inherited from different parental species are typically not identical and have, in many cases, quite different functional properties (Chen 2007). Furthermore, hybrid phenotypes may be affected by gene dosage, as the presence of different gene copy numbers can affect regulation and expression (Chen 2007; Yao et al. 2013).

The natural S. pastorianus hybrids, resulting from the hybridization of Saccharomyces cerevisiae and Saccharomyces eubayanus, have been divided into two groups based on their DNA content, Saaz/Group I and Frohberg/Group II, and these differ functionally in a number of respects (Dunn and Sherlock 2008; Gibson et al. 2013a; Liti et al. 2005). The allotriploid Saaz strains, which have retained proportionally more DNA derived from the $S$. eubayanus parent (Walther et al. 2014), tend to possess fermentation characteristics more similar to S. eubayanus, while the allotetraploid Frohberg strains, with proportionally more DNA from the S. cerevisiae parent (Walther et al. 2014; Nakao et al. 2009), are phenotypically more similar to $S$. cerevisiae ale strains (Gibson et al. 2013a). Recently, genome sequencing of a range of industrial lager yeast strains revealed chromosome copy number variation among Frohberg strains which seemed to directly influence certain phenotypic differences (Van den Broek et al. 2015). Polyploidy and greater gene copy numbers also tend to increase the ability of microbes to resist environmental stresses, which in brewing could comprise, e.g., high osmotic stress and high alcohol concentrations from very high gravity wort (Chen 2007; Gibson et al. 2007; Gibson 2011; Schoenfelder and Fox 2015; Storchova 2014). This was also reflected in a recent study on lager hybrids, where allotriploid hybrids tended to perform better than allodiploid ones (Mertens et al. 2015). Hence, for de novo lager yeast hybrids, a higher ploidy level and thus greater gene copy number could result in increased performance and stress tolerance.

The main yeast-derived flavor compounds in beer are higher alcohols and esters. Esters especially, with their fruity and floral aromas, are considered to contribute a desirable and vital component of beer flavor (Pires et al. 2014). They are mainly formed during fermentation through intracellular enzymatic condensation reactions between alcohols and acylCoA, and are divided into two classes: acetate esters and fatty acid ethyl esters. While ester formation is affected by several environmental factors, such as temperature, $\mathrm{pH}$, precursor availability, oxygen concentration, and yeast growth (Hiralal et al. 2014; Pires et al. 2014; Stribny et al. 2015; Yoshioka and Hashimoto 1981), it is also dependent on the expression and enzyme activities of various transferase-encoding genes: ATF1 and ATF2 for acetate esters (Verstrepen et al. 2003; Zhang et al. 2013), and EHT1 and EEB1 for fatty acid ethyl esters (Saerens et al. 2006, 2008). The expression levels of $A T F 1$ and ATF2 especially seem to be directly correlated with the concentrations of acetate esters in beer (Saerens et al. 2008). In lager yeast, these genes typically occur in two allelic forms, with one derived from the $S$. cerevisiae parent and the other from the S. eubayanus parent. Recent gene expression studies on lager yeast have revealed variation in expression and product activity of orthologous genes (Bolat et al. 2013; Gibson et al. 2015; He et al. 2014; Horinouchi et al. 2010), suggesting that aroma formation by de novo lager yeast hybrids may be directly affected by the expression of aromarelated orthologous genes inherited from each parent strain. Also, it is hypothesized that aroma formation is affected by the ploidy level of these hybrids, as increased gene copy numbers typically result in increased expression (Yamada et al. 2010).

Here, we generated lager yeast hybrids with different ploidy levels (allodiploid, allotriploid, and allotetraploid) by crossing an $S$. cerevisiae ale strain with the $S$. eubayanus type strain through either spore-to-spore mating or rare mating (Pérez-Través et al. 2012; Steensels et al. 2014b). The contributions of the respective parental genomes to the hybrid genomes were determined by sequencing. The performance of these hybrids with respect to each other and the parent strains was characterized in 2 -L fermentations using 15 and $25^{\circ} \mathrm{P}$ wort. The fermenting wort and resulting beers were analyzed for aroma compounds, vicinal diketones, and sugar content, while transcript analysis, viability tests, and flocculation assays were performed on the strains. The aim was to investigate to what extent the DNA content of de novo lager yeast hybrids affects fermentation performance, aroma production, and resistance towards intensification of fermentation conditions. Furthermore, the relationship between gene expression and aroma formation in the strains was elucidated. It is expected that results will facilitate the creation of future hybrid brewing yeasts with specific properties.

\section{Materials and methods}

\section{Yeast strains}

The two parental strains were $S$. cerevisiae VTT-A81062 (VTT Culture Collection, Finland), an industrial ale yeast strain, and the S. eubayanus type strain VTT-C12902 (VTT Culture Collection, Finland; deposited as CBS12357 at CBSKNAW Fungal Biodiversity Centre, Netherlands). The three 
hybrid strains $(\mathrm{A} 81062 \times \mathrm{C} 12902)$, i.e., allodiploid, allotriploid, and allotetraploid strains, that were chosen for further characterization were named 'Hybrid A2', 'Hybrid B3', and 'Hybrid C4', respectively. Prior to hybridization, natural auxotrophic mutants (lys- and ura-) of the parental strains were selected on $\alpha$-aminoadipic and 5-fluoroorotic acid agar plates, respectively (Boeke et al. 1987; Zaret and Sherman 1985). Auxotrophy was confirmed by the inability to grow on minimal selection agar medium $(0.67 \%$ Yeast Nitrogen Base without amino acids, $3 \%$ glycerol, $3 \%$ ethanol, and $2 \%$ agar).

\section{Generation of interspecific hybrids}

The allodiploid interspecific hybrid 'Hybrid A2', between a lys- isolate of $S$. cerevisiae A81062 and a ura- isolate of S. eubayanus C12902, was produced using spore-to-spore mating. First, ascospores of the auxotrophic mutants were generated on sporulation agar ( $1 \%$ potassium acetate, $10 \mathrm{mg}$ $\mathrm{L}^{-1}$ lysine and uracil, $2 \%$ agar) as described by Krogerus et al. (2015a). Ascus walls were digested with $1 \mathrm{mg} \mathrm{mL}^{-1}$ Zymolyase 100T (US Biological, USA), after which spores from the different parental strains were dissected and placed next to each other on YPD agar plates (1\% yeast extract, $2 \%$ peptone, $2 \%$ glucose, and $2 \%$ agar) using a micromanipulator (Singer Instruments, UK). The plates were incubated at $25{ }^{\circ} \mathrm{C}$ for 3 days, after which any emerging colonies were replated on minimal selection agar, and incubated at $25{ }^{\circ} \mathrm{C}$ for 5 days. Any colonies emerging on the minimal selection agar were regarded as potential hybrids.

The allotriploid interspecific hybrid 'Hybrid B3', between a ura- isolate of $S$. cerevisiae A81062 and a lys- isolate of S. eubayanus C12902, was produced using rare mating. A culture of S. cerevisiae A81062 ura- was grown overnight at $25^{\circ} \mathrm{C}$ by inoculating a single colony into $50 \mathrm{~mL}$ of YPM $(1 \%$ yeast extract, $2 \%$ peptone, $2 \%$ maltose). The culture was centrifuged at $5000 \times \mathrm{g}$ for $5 \mathrm{~min}$, after which the cells were first washed once and then resuspended in sterile $\mathrm{H}_{2} \mathrm{O}$ to a concentration of $10 \mathrm{~g}$ centrifuged wet yeast mass $\mathrm{L}^{-1}$. Ascospores of $S$. eubayanus C12902 lys- were scraped off the agar into $1 \mathrm{~mL}$ sterile reverse-osmosis purified $\mathrm{H}_{2} \mathrm{O}$ in $2 \mathrm{~mL}$ Eppendorf tubes. Tubes were centrifuged at $5000 \times \mathrm{g}$ for $5 \mathrm{~min}$ and the supernatant was removed. Ascus walls were digested by the addition of $50 \mu \mathrm{L} 1 \mathrm{mg} \mathrm{mL}{ }^{-1}$ Zymolyase $100 \mathrm{~T}$ and incubation at $30^{\circ} \mathrm{C}$ for $20 \mathrm{~min}$. Two hundred microliters of sterile $\mathrm{H}_{2} \mathrm{O}$ was then added, and the cells and spores were resuspended by vortexing. One hundred microliters of the resulting suspensions from both parental strains, with complementary auxotrophic markers, was transferred together to $1 \mathrm{~mL}$ YPM medium in a sterile $2 \mathrm{~mL}$ Eppendorf tube. Tubes were vortexed and incubated statically at $25{ }^{\circ} \mathrm{C}$ for 5 days. After incubation, the tubes were centrifuged at $5000 \times g$ for $5 \mathrm{~min}$ and the supernatant was removed. Five hundred microliters of starvation medium $(0.1 \%$ yeast extract and $0.1 \%$ glucose) was added, and tubes were incubated for at least $2 \mathrm{~h}$ at room temperature. Tubes were then vortexed and $100 \mu \mathrm{L}$ aliquots were spread onto minimal selection agar (without uracil or lysine). Plates were incubated at $25^{\circ} \mathrm{C}$ for 5 days and any colonies emerging on the minimal selection agar were regarded as potential hybrids.

The allotetraploid interspecific hybrid 'Hybrid C4', between a ura-isolate of $S$. cerevisiae A81062 and a lys-isolate of $S$. eubayanus $\mathrm{C} 12902$, was also produced using rare mating. Hybrid generation was carried out essentially as described above for the allotriploid hybrid. However, instead of using a suspension of S. eubayanus C12902 lys- spores, a suspension of vegetative cells was used. A culture of $S$. eubayanus C12902 lys- was grown overnight at $25^{\circ} \mathrm{C}$ by inoculating a single colony into $50 \mathrm{~mL}$ of YPM. The culture was centrifuged at $5000 \times g$ for $5 \mathrm{~min}$, after which the cells were first washed once and then resuspended in sterile $\mathrm{H}_{2} \mathrm{O}$ to a concentration of $10 \mathrm{~g}$ centrifuged wet yeast mass $\mathrm{L}^{-1}$.

\section{Confirmation of hybrid status by PCR and RFLP}

The hybrid status of isolates was confirmed by PCR as described in Krogerus et al. (2015a). Briefly, the rDNA ITS region was amplified using the primers ITS1 (5'TCCGTAGGTGAACCTGCGG-3') and ITS 4 (5'TCCTCCGCTTATTGATATGC-3'), and amplicons were digested using the HaeIII restriction enzyme (New England BioLabs, USA) as described previously (Pham et al. 2011). Amplification of the S. eubayanus-specific FSY1 gene (amplicon size $228 \mathrm{bp}$ ) and the S. cerevisiae-specific MEX67 gene (amplicon size $150 \mathrm{bp}$ ) was also performed on the DNA extracted from the hybrid strains using the primers SeubF3 (5'-GTCCCTGTACCAATTTAATATTGCGC-3'), SeubR2 (5'-TTTCACATCTCTTAGTCTTTTCCAGACG-3'), ScerF2 (5'-GCGCTTTACATTCAGATCCCGAG-3'), and ScerR2 (5'-TAAGTTGGTTGTCAGCAAGATTG-3') as described by Muir et al. (2011) and Pengelly and Wheals (2013).

\section{DNA content by flow cytometry}

Flow cytometry was performed on the yeast strains essentially as described by Haase and Reed (2002). Cells were grown overnight in YPD medium ( $1 \%$ yeast extract, $2 \%$ peptone, $2 \%$ glucose), and approximately $1 \times 10^{7}$ cells were washed with $1 \mathrm{~mL}$ of $50 \mathrm{mM}$ citrate buffer. Cells were then fixed with cold $70 \%$ ethanol and incubated at room temperature for $1 \mathrm{~h}$. Cells were then washed with $50 \mathrm{mM}$ citrate buffer ( $\mathrm{pH} 7.2$ ), resuspended in $50 \mathrm{mM}$ citrate buffer containing $0.25 \mathrm{mg} \mathrm{mL}^{-1}$ RNAse A, and incubated overnight at $37{ }^{\circ} \mathrm{C}$. Proteinase $\mathrm{K}$ ( $1 \mathrm{mg} \mathrm{mL}^{-1}$ ) was then added, and cells were incubated for $1 \mathrm{~h}$ at $50{ }^{\circ} \mathrm{C}$. Cells were then stained with SYTOX Green ( $2 \mu \mathrm{M}$; Life Technologies, USA), and their DNA content 
was determined using a FACSAria cytometer (Becton Dickinson, USA). DNA contents were estimated by comparing fluorescence intensities with those of $S$. cerevisiae haploid (CEN.PK113-1A) and diploid (CEN.PK) reference strains. Measurements were performed on duplicate independent yeast cultures, and 100,000 events were collected per sample during flow cytometry.

\section{Genome sequencing and analysis}

In order to create a reference sequence to which hybrid sequences would be compared, S. cerevisiae strain A81062 was sequenced by BaseClear (Leiden, Netherlands). In brief, a hybrid approach of PacBio $10 \mathrm{~kb}$ genomic library sequencing with a PacBio RSII instrument and Illumina NexteraXT pairend 150 bp library sequencing with a HiSeq 2500 instrument was carried out. A hybrid assembly of the produced data was also done by BaseClear (Leiden, Netherlands). In brief, Illumina reads were de novo assembled with CLC Genomics Workbench and the assembly aligned to PacBio reads with BLASR (Chaisson and Tesler 2012). Information from this alignment was then used to scaffold the contigs with SSPACE-LongRead scaffolder (Boetzer and Pirovano 2014), and gaps in the assembly were filled with GapFiller (Boetzer and Pirovana 2012).

For subsequent analysis steps, the de novo assembly provided by BaseClear was further reference assembled by Ragout (Kolmogorov et al. 2014) to S. cerevisiae S288C genome version R64-2-1 (Engel et al. 2013) in order to combine scaffolds to chromosomes. Finally, the processed $S$. cerevisiae A81062 and S. eubayanus FM1318 (a monosporic derivative of C12902; Baker et al. 2015) genomes were concatenated to create a single reference genome. An integrative yeast gene annotation pipeline was set up at Liti Lab (full technical detail will be published separately) in order to combine different existing annotation approaches to form an evidenceleveraged final annotation. RATT (Otto et al. 2011), YGAP (Proux-Wéra et al. 2012), and Maker (Holt and Yandell 2011) were used for gene annotation independently. Then their results were further integrated by EVM (Haas et al. 2008). Proteomes and CDS sequences of several representative sensu stricto species ( $S$. cerevisiae, S. paradoxus, S. mikatae, S. bayanus, S. kudriavzevii, and S. eubayanus) were retrieved according to Scannell et al. (2011) and Baker et al. (2015) and used in our annotation pipeline.

Hybrids A2, B3, and C4 were sequenced by Biomedicum Genomics (Helsinki, Finland). In brief, an Illumina NexteraXT pair-end 150 bp library was prepared for each hybrid and sequencing was carried out with a NextSeq 500 instrument. Pair-end reads from the NextSeq 500 sequencing were quality-analyzed with FastQC (http://www. bioinformatics.babraham.ac.uk/projects/fastqc/) and trimmed and filtered with Skewer (Jiang et al. 2014). Alignment, re- alignment, and variant analysis was carried out using SpeedSeq's (Chiang et al. 2015) FreeBayes SNP prediction and CNVnator copy number variation prediction modules (Abyzov et al. 2011; Garrison and Marth 2012). SNPs predicted by FreeBayes with less than five left and right aligning reads were discarded. FreeBayes detected two types of SNPs: (a) heterozygous - two different alleles of the SNP are present in equal proportions in the hybrid, or (b) homozygous - a SNP only had an allele different than the reference sequence. Variable copy number regions predicted by CNVnator with higher e-value than 0.001 were discarded. Prior to SpeedSeq variant analysis, alignments were filtered to a minimum MAPQ of 50 with SAMtools (Li et al. 2009). Quality of alignments was assessed with QualiMap (GarcíaAlcalde et al. 2012). In order to exclude repeated regions from the genome during variant analysis, $S$. cerevisiae repetitive regions were retrieved from SGD (Engel et al. 2013) and matched to the concatenated reference genome. Additional copy-number analysis was carried out with cn.MOPS (Klambauer et al. 2012). According to author's instructions, alignments for cn.MOPS were carried out with Bowtie2, mapping a read to one random best mapping position. Scaffolds shorter than 100,000 bp were discarded. Window size was set to $1000 \mathrm{bp}$.

In order to count chromosomal copy numbers, the median of read coverage for each nucleotide of a gene was calculated and normalized with sample wise median read coverage of all genes. The median of all genes of a chromosome was then calculated and multiplied by a ploidy specific factor as determined by flow cytometry (allotetraploid Hybrid C4: 2, allotriploid Hybrid B3: 1.5, and allodiploid Hybrid A2: 1) for final chromosome copy numbers. Count analysis was done using R-libraries GenomicRanges, GenomicAlignments, Rsamtools, and GenomicFeatures (Lawrence et al. 2013; Morgan et al. 2010).

\section{Quantitative PCR for copy number analysis}

The relative copy numbers of the $S$. cerevisiae- and S. eubayanus-derived ATF1, ATF2, and EEB1 genes in the hybrid strains were estimated with quantitative PCR of genomic DNA. DNA was extracted from the strains using a GeneJET Genomic DNA Purification kit (Thermo Scientific, USA) with an additional cell disruption step using acidwashed glass beads (Sigma-Aldrich, Finland). The plasmid pUG66 was used as an internal standard (Gueldener et al. 2002). The species-specific primers (see Table S2 in Supplementary material) were designed using the S. cerevisiae A81062 and S. eubayanus FM1318 (Baker et al. 2015) reference genomes. Species-specific primers for EHT1 and BAT1 could not be obtained and were thus excluded from the analysis. The efficiencies $(E)$ of the qPCR assays (ranging from 1.96 to 2.00) for each primer pair were 
calculated using the formula $10^{(-1 / m)}$, where $m$ is the slope of the line of the threshold cycle $\left(C_{T}\right)$-versus-log dilution plot of the DNA template (5 pg to 50 ng input DNA) (Pfaffl 2001). The PCRs were performed using a LightCycler ${ }^{\circledR} 480$ SYBR Green I Master mix (Roche Diagnostics, Switzerland) on a LightCycler ${ }^{\circledR} 480$ II instrument (Roche Diagnostics, Switzerland) in four independent replicates. The following program was used: pre-incubation $\left(95^{\circ} \mathrm{C}\right.$ for $\left.5 \mathrm{~min}\right)$, amplification cycle repeated 45 times $\left(95^{\circ} \mathrm{C}\right.$ for $10 \mathrm{~s}, 60^{\circ} \mathrm{C}$ for $10 \mathrm{~s}$, $72{ }^{\circ} \mathrm{C}$ for $10 \mathrm{~s}$ with a single fluorescence measurement), melting curve program $\left(65-97^{\circ} \mathrm{C}\right.$ with continuous fluorescence measurement), and finally a cooling step to $40{ }^{\circ} \mathrm{C}$. Data analysis was performed using the supplied LightCycler ${ }^{\circledR} 480$ Software, version 1.5 (Roche Diagnostics, Switzerland). The copy numbers of the target genes in the hybrid strains relative to the parent strains were calculated using the formula (Pfaffl 2001):

Ratio $=\frac{\left(E_{\text {target }}\right)^{\Delta C_{T, \text { target }}(\text { control-sample })}}{\left(E_{\text {reference }}\right)^{\Delta C_{T, \text { reference }}(\text { control-sample })}}$

\section{Fermentations}

The three hybrid and two parental strains were characterized in fermentations performed at $15{ }^{\circ} \mathrm{C}$ in both a $15^{\circ} \mathrm{P}$ high gravity wort and a $25^{\circ} \mathrm{P}$ very high gravity wort. Yeast was propagated essentially as described previously (Krogerus and Gibson 2013a), with the use of a "Generation 0" fermentation prior to the actual experimental fermentations. The experimental fermentations were carried out in duplicate, in 2-L cylindroconical stainless steel fermenting vessels, containing $1.5 \mathrm{~L}$ of wort medium. The $15^{\circ} \mathrm{P}$ wort $(69 \mathrm{~g}$ maltose, $24.5 \mathrm{~g}$ maltotriose, $21.1 \mathrm{~g}$ glucose, and $5.4 \mathrm{~g}$ fructose per liter) was produced at the VTT Pilot Brewery from barley malt and had a free amino nitrogen (FAN) content of $372 \mathrm{mg} \mathrm{L}^{-1}$. The $25^{\circ} \mathrm{P}$ wort (127 g maltose, $45.5 \mathrm{~g}$ maltotriose, $33.8 \mathrm{~g}$ glucose, and $9.2 \mathrm{~g}$ fructose per liter) was produced at the VTT Pilot Brewery from barley malt and Maltax 10 malt extract (Senson Oy, Finland), and had a FAN content of $602 \mathrm{mg}$ $\mathrm{L}^{-1}$. Yeast was inoculated at a rate of $15 \times 10^{6}$ and $25 \times 10^{6}$ viable cells $\mathrm{mL}^{-1}$ to the 15 and $25^{\circ} \mathrm{P}$ worts, respectively. The worts were oxygenated to $15 \mathrm{mg} \mathrm{L}^{-1}$ prior to pitching (Oxygen Indicator Model 26073 and Sensor 21158; Orbisphere Laboratories, Switzerland). The fermentations were carried out at $15{ }^{\circ} \mathrm{C}$ either until an apparent attenuation of $80 \%$ (corresponding to approximately $6.8 \%$ and $12 \%$ $\mathrm{ABV}$ in the 15 and $25^{\circ} \mathrm{P}$ fermentations, respectively) was reached, until no change in residual extract was observed for $24 \mathrm{~h}$ or for a maximum of 23 days if the preceding criteria were not met.
Wort samples were drawn regularly from the fermentation vessels aseptically and placed directly on ice, after which the yeast was separated from the fermenting wort by centrifugation $\left(9000 \times g, 10 \mathrm{~min}, 1^{\circ} \mathrm{C}\right)$. Samples for yeast-derived flavor compounds, fermentable sugars, and total diacetyl were drawn as above when $33 \%$ apparent attenuation (approximately 2.8 and $5.2 \% \mathrm{ABV}$ in the 15 and $25^{\circ} \mathrm{P}$ fermentations, respectively) had been reached, $60 \%$ apparent attenuation (approximately 5.0 and $9.0 \% \mathrm{ABV}$ in the 15 and $25^{\circ} \mathrm{P}$ fermentations, respectively) had been reached, and from the beer. Yeast viability was measured from the yeast that was collected at the end of the fermentations using a Nucleocounter ${ }^{\circledR}$ YC- $100^{\mathrm{TM}}$ (ChemoMetec, Denmark).

Flocculation of the yeast strains was evaluated using a modified Helm's assay essentially as described by D'Hautcourt and Smart (1999). Cultures recovered from fermentation were washed twice with $0.5 \mathrm{M}$ EDTA $(\mathrm{pH} 7)$ to break the cell aggregates and then diluted to an $\mathrm{OD}_{600}$ of 0.4 . Flocculation was assayed by first washing yeast pellets with $4 \mathrm{mM} \mathrm{CaCl}_{2} \cdot 2 \mathrm{H}_{2} \mathrm{O}$ solution and resuspending them in $1 \mathrm{~mL}$ of flocculation solution containing $4 \mathrm{mM} \mathrm{CaCl}_{2} \cdot 2 \mathrm{H}_{2} \mathrm{O}, 6.8 \mathrm{~g}$ $\mathrm{L}^{-1}$ sodium acetate, $4.05 \mathrm{~g} \mathrm{~L}^{-1}$ acetic acid, and $4 \%(v / v)$ ethanol (pH 4.5). Yeast cells in control tubes were resuspended in 0.5 M EDTA $(\mathrm{pH}$ 7). After a sedimentation period of $10 \mathrm{~min}$, samples $(200 \mu \mathrm{L})$ were taken from just below the meniscus and dispersed in $10 \mathrm{mM}$ EDTA $(800 \mu \mathrm{L})$. The absorbance at $600 \mathrm{~nm}$ was measured, and percentage of flocculation was determined from the difference in absorbance between control and flocculation tubes.

\section{Ethanol tolerance}

The ethanol tolerance during wort fermentations of the parental strains and hybrid strains was tested in small-scale fermentations $(35 \mathrm{~mL})$ performed in airlock-capped $50-\mathrm{mL}$ centrifuge tubes. Three worts of $10{ }^{\circ} \mathrm{P}$ original extract were prepared by diluting $25^{\circ} \mathrm{P}$ all-malt wort with deionized water and ethanol: control ( $0 \%$ ethanol), $5 \%$ ethanol, and $10 \%$ ethanol. Fermentations were carried out in duplicate at $20{ }^{\circ} \mathrm{C}$ and were started by adding $15 \times 10^{6}$ viable cells $\mathrm{mL}^{-1}$ to each wort. Here, the higher fermentation temperature was chosen in order to not bias the results. Fermentation progress was monitored by weight loss and final alcohol level $(\% v / v)$. Weight losses during fermentation in the worts supplemented with ethanol were expressed relative to that of the control wort.

\section{Yeast transcriptional analysis}

Samples for yeast transcriptional analysis were taken from the $15{ }^{\circ} \mathrm{P}$ fermentations $24 \mathrm{~h}$ after pitching, after $33 \%$ apparent attenuation had been reached, and after $60 \%$ apparent attenuation had been reached. The yeast was harvested from the fermentation vessels by anaerobically withdrawing wort containing 
50-200 mg fresh mass of yeast. Samples were briefly centrifuged $\left(9000 \times g, 3 \mathrm{~min}, 1^{\circ} \mathrm{C}\right)$ and yeast pellets were washed with ice-cold RNAse-free (dimethyl pyrocarbonate (DMPC)-treated) water, transferred to tared screw-cap cryovials, and immediately frozen in liquid nitrogen before storage at $-80^{\circ} \mathrm{C}$. This sampling procedure took less than $10 \mathrm{~min}$. Transcriptional analysis was performed with the TRAC assay essentially as described earlier (Rautio et al. 2007). Sample tubes were weighed to calculate the fresh yeast mass. Frozen yeast samples were suspended (100$200 \mathrm{mg}$ fresh weight $\mathrm{mL}^{-1}$ ) in lysis buffer (ValiRx Finland Oy, Finland). Yeast was disrupted with $500 \mu \mathrm{L}$ of acid-washed glass beads (Sigma-Aldrich, Finland) twice in a MagNA Lyzer cell homogenizer (Roche Diagnostics, Switzerland) for $45 \mathrm{~s}$ at full speed. Hybridization reaction mixtures $(125 \mu \mathrm{L})$ contained yeast lysate (100 $\mu \mathrm{g}$ biomass; $100-150$ ng polyA RNA), 4 pmol biotinylated oligo(dT) capture probe (Ella Biotech), 0.5 pmol each of labeled detection probe (ValiRx Finland Oy, Finland), $75 \mu \mathrm{L}$ HybMix (ValiRx Finland Oy, Finland), and 1.5 fmol of ssDNA as internal standard (ValiRx Finland Oy, Finland). The hybridizations were carried out in 96-well PCR plates (ABgene, Epsom, UK) at $60{ }^{\circ} \mathrm{C}$ for $60 \mathrm{~min}$. The steps following hybridization, including affinity capture, washing, and elution, were automated with a magnetic bead particle processor KingFisher 96 (Thermo Electron, Vantaa, Finland) in 96-well plates as follows: (1) affinity capture of hybridized RNA targets to $50 \mu \mathrm{g}$ of streptavidin-coated Sera-Mag SpeedBeads (Thermo Fisher Scientific, USA) for $15 \mathrm{~min}$ at room temperature, (2) washing of the beads five times for $1.5 \mathrm{~min}$ in $100 \mu \mathrm{L}$ of Wash Buffer (ValiRx Finland Oy, Finland) at room temperature, and (3) elution of probes with $10 \mu \mathrm{L}$ of formamide (Applied Biosystems, Foster City, CA, USA) for $10 \mathrm{~min}$ at $37{ }^{\circ} \mathrm{C}$. The eluates were analyzed by capillary electrophoresis with an ABI PRISM 3730 Genetic Analyzer (Applied Biosystems, Foster City, CA, USA). To calibrate the separation of the detection probes by size, GeneScan-120LIZ size standard (Applied Biosystems, Foster City, CA, USA) was added to each sample. The identity of the probes was determined by the migration speed and the quantity by the peak area. To minimize non-biological variation in the TRAC assay, the signal intensities measured for the target genes were normalized between samples using the signal measured for the ssDNA internal standard. Oligonucleotide probes (for list, see Table S1 in Supplementary material) were designed and validated as described in previous studies (Gibson et al. 2013b, 2015). The TRAC assay was performed on both orthologues (S. cerevisiae- and S. eubayanus-derived) of five genes previously reported to contribute to ester formation ATF1, ATF2, EHT1, EEB1, and BAT1 (Lilly et al. 2006; Saerens et al. 2006, 2008; Verstrepen et al. 2003; Zhang et al. 2013).

\section{Wort and beer analysis}

The specific gravity, alcohol level $(\% v / v)$, and $\mathrm{pH}$ of samples were determined from the centrifuged and degassed fermentation samples using an Anton Paar Density Metre DMA $5000 \mathrm{M}$ with Alcolyzer Beer ME and pH ME modules (Anton Paar GmbH, Austria).

The yeast dry mass content of the samples (i.e., yeast in suspension) was determined by washing the yeast pellets gained from centrifugation twice with $25 \mathrm{~mL}$ deionized $\mathrm{H}_{2} \mathrm{O}$ and then suspending the washed yeast in a total of $6 \mathrm{~mL}$ deionized $\mathrm{H}_{2} \mathrm{O}$. The suspension was then transferred to a preweighed porcelain crucible, and was dried overnight at $105^{\circ} \mathrm{C}$ and allowed to cool in a desiccator before the change of mass was measured.

Concentrations of fermentable sugars (glucose, fructose, maltose, and maltotriose) were measured by HPLC using a Waters 2695 Separation Module and Waters System Interphase Module liquid chromatograph coupled with a Waters 2414 differential refractometer (Waters Co., Milford, MA, USA). An Aminex HPX-87H Organic Acid Analysis Column $(300 \times 7.8 \mathrm{~mm}$; Bio-Rad, USA $)$ was equilibrated with $5 \mathrm{mM} \mathrm{H}_{2} \mathrm{SO}_{4}$ (Titrisol, Merck, Germany) in water at $55^{\circ} \mathrm{C}$, and samples were eluted with $5 \mathrm{mM} \mathrm{H}_{2} \mathrm{SO}_{4}$ in water at a $0.3 \mathrm{~mL} \mathrm{~min}^{-1}$ flow rate.

Yeast-derived flavor compounds were determined by headspace gas chromatography with flame ionization detector (HSGC-FID) analysis. Four-milliliter samples were filtered $(0.45 \mu \mathrm{m})$ and incubated at $60^{\circ} \mathrm{C}$ for $30 \mathrm{~min}$, and then $1 \mathrm{~mL}$ of gas phase was injected (split mode; $225^{\circ} \mathrm{C}$; split flow of

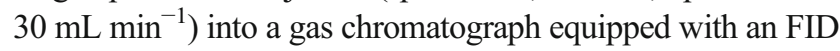
detector and headspace autosampler (Agilent 7890 Series; Palo Alto, CA, USA). Analytes were separated on a HP-5 capillary column $(50 \mathrm{~m} \times 320 \mu \mathrm{m} \times 1.05 \mu \mathrm{m}$ column; Agilent, USA). The carrier gas was helium (constant flow of $1.4 \mathrm{~mL} \mathrm{~min}^{-1}$ ). The temperature program was $50{ }^{\circ} \mathrm{C}$ for $3 \mathrm{~min}, 10^{\circ} \mathrm{C} \mathrm{min}{ }^{-1}$ to $100{ }^{\circ} \mathrm{C}, 5^{\circ} \mathrm{C} \mathrm{min}^{-1}$ to $140{ }^{\circ} \mathrm{C}, 15^{\circ} \mathrm{C} \mathrm{min}^{-1}$ to $260^{\circ} \mathrm{C}$ and then isothermal for $1 \mathrm{~min}$. Compounds were identified by comparison with authentic standards and were quantified using standard curves. 1-Butanol was used as internal standard.

Total diacetyl (free and acetohydroxy acid form) in the centrifuged fermentation samples was measured according to Analytica-EBC method 9.10 (European Brewery Convention 2004). Samples were heated to $60{ }^{\circ} \mathrm{C}$ and kept at this temperature for $90 \mathrm{~min}$. Heating to $60^{\circ} \mathrm{C}$ results in the conversion of $\alpha$ acetolactate to diacetyl. The samples were then analyzed by headspace gas chromatography using a gas chromatograph equipped with a $\mu \mathrm{ECD}$ detector and headspace autosampler (Agilent 7890 Series; Palo Alto, CA, USA). Analytes were separated on a HP-5 capillary column $(50 \mathrm{~m} \times 320 \mu \mathrm{m} \times 1.05 \mu \mathrm{m}$ column; Agilent, USA). 2,3-Hexanedione was used as an internal standard.

\section{Fermentation data analysis and visualization}

Statistical analysis was performed with R (http://www.rproject.org/) by using one-way ANOVA and Tukey's test. 
Heat maps of the concentrations of yeast-derived flavor compounds in the beers were generated in $\mathrm{R}$ based on $\mathrm{Z}$-scores. The z-scores $(z)$ were calculated as $z=(x-\mu) / \sigma$, where $x$ is the concentration of an aroma compound in a particular beer, $\mu$ is the mean concentration of that aroma compound in all beers, and $\sigma$ is the standard deviation of concentration of that aroma compound in all beers.

Correlations between the maximum transcription level of the monitored genes and the concentrations of aroma compounds in the beers fermented from the $15^{\circ} \mathrm{P}$ wort were estimated with multiple linear regression followed by ANOVA to test for significance. The maximum transcription levels were fitted to the concentrations of the aroma compounds as follows:

$Y_{i}=\beta_{S c, i j} \cdot X_{S c, j}+\beta_{S e, j} \cdot X_{S e, i j}+\beta_{0}$

where $Y_{i}$ is the concentration of aroma compound $i ; X_{S c, j}$ and $X_{S e, j}$ are the maximum transcription levels of the $S$. cerevisiae- and $S$. eubayanus-derived orthologues of gene $j$, respectively; and $\beta_{S c, i j}, \beta_{S e, i j}$, and $\beta_{0}$ are the regression coefficients.

\section{Nucleotide sequence accession numbers}

The $S$. cerevisiae A81062 reads have been submitted to NCBI-SRA under BioProject number PRJNA301545 and the assembled genome to NCBI-WGS under BioProject number PRJNA301545. The Illumina reads from hybrid strains Hybrid A2, Hybrid B3, and Hybrid C4 have been submitted to NCBI-SRA under BioProject number PRJNA301546.

\section{Results}

\section{Hybrid generation and confirmation}

Interspecific hybrids between the $S$. cerevisiae A81062 and S. eubayanus C12902 parent strains were successfully generated using both spore-to-spore mating and rare mating. From spore-to-spore mating, a hybridization frequency of $3.6 \%$ was achieved, while rare mating resulted in the emergence of an average of 381 and 4 colonies (corresponding to hybridization frequencies of approximately $7.6 \times 10^{-6}$ and $1.0 \times 10^{-7}$, respectively) on the selection agar from $1 \mathrm{~mL}$ of hybridization culture for allotriploid (C12902 spores and A81062 vegetative cells) and allotetraploid generation (C12902 and A81062 vegetative cells), respectively. Hybrid status of these isolates was confirmed with both ITS-PCR combined with RFLP and amplification of FSY1 and MEX67 genes using S. eubayanus- and $S$. cerevisiae-specific primers (Fig. S1 in Supplementary material). Three hybrids (Hybrid A2 from spore-to-spore mating,
Hybrid B3 from rare-mating with C12902 spores, and Hybrid $\mathrm{C} 4$ from rare-mating with vegetative cells) were then selected for further characterization. Flow cytometry confirmed that Hybrid A2 was diploid, Hybrid B3 was triploid, and Hybrid C4 was tetraploid (Fig. S2 in Supplementary material).

The de novo sequencing of the diploid $S$. cerevisiae A81062 resulted into 40 scaffolds which span a total genome size of $12 \mathrm{Mbp}$. These were further assigned to 16 chromosomes and the mitochondrial genome by reference assembly with Ragout (Kolmogorov et al. 2014). A more detailed description of the S. cerevisiae A81062 genome will be published separately. Together with the $S$. eubayanus genome (Baker et al. 2015), these sequences were used as the reference genome for hybrid analysis. Chromosome counts of the hybrid genomes were calculated from the median of normalized median read coverage of each chromosome's genes (Table 1). Counts of the genes monitored with transcriptional analysis were also estimated based on the median read coverage and found to be equal to the count of their associated chromosome. These gene counts were further supported by qPCR analysis (Table S3 in Supplementary material). Furthermore, this analysis was supported by FreeBayes SNP prediction and CNVnator copy number variation module of the SpeedSeqpipeline (Figs. S3-S10 in Supplementary material show genome coverage, FreeBayes SNP predictions, and CNVnator copy number variation predictions).

The $S$. cerevisiae subgenome chromosomes of the allotetraploid Hybrid C4 and allotriploid Hybrid B3 almost exclusively contain heterozygous SNPs (Figs. S6 and S8 in Supplementary material), which supports the fact that two copies of these chromosomes were present in these hybrids as predicted by read coverage analysis. An exception was chromosome III that contained only homozygous SNPs and that read coverage analysis and CNVnator also detected as a single copy (Table 1). In addition, $S$. cerevisiae subgenome chromosome X appears chimeric based on its SNP distribution in Hybrids C4 and B3. Read coverage analysis revealed that the allodiploid Hybrid A2 contained one set of chromosomes derived from S. cerevisiae A81062. This was again supported by the SNPs, which were found to be homozygous within the $S$. cerevisiae subgenome of Hybrid A2 (Table 1 and Fig. S4 in Supplementary material). SNPs in the S. eubayanus subgenome are too rare to provide support for chromosome copy numbers. In all three hybrids, only $2 \%$ of the SNPs occur in the $S$. eubayanus subgenome. Accordingly, based on S. eubayanus genome data from Bioproject PRJNA264003 (Hebly et al. 2015), we estimate that the S. cerevisiae A81062 genome has an almost 200 times higher ratio of heterozygosity than $S$. eubayanus C12902. Read coverage analyses show that the mitochondria are derived from S. eubayanus in Hybrid C4 and Hybrid B3 and from S. cerevisiae in Hybrid A2 (Fig. S10 in Supplementary material). 
Table 1 Chromosome copy numbers of the Hybrid A2, Hybrid B3, and Hybrid C4 strains

\begin{tabular}{|c|c|c|c|c|c|c|c|c|}
\hline \multirow[t]{2}{*}{ Chromosome } & \multicolumn{2}{|c|}{ Genes located on chromosome } & \multicolumn{2}{|c|}{ Hybrid A2 } & \multicolumn{2}{|c|}{ Hybrid B3 } & \multicolumn{2}{|c|}{ Hybrid C4 } \\
\hline & Scer & Seub & Scer & Seub & Scer & Seub & Scer & Seub \\
\hline I & & & 1 & 1 & 2 & 1 & 2 & 2 \\
\hline II & Sc-EHT1 & & 1 & 1 & 2 & 1 & 2 & 2 \\
\hline III & & & 1 & 1 & 1 & 1 & 1 & 2 \\
\hline IV & & Se-EHT1 & 1 & 1 & 2 & 1 & 2 & 2 \\
\hline $\mathrm{V}$ & & & 1 & 1 & 2 & 1 & 2 & 2 \\
\hline VI & & & 1 & 1 & 2 & 1 & 2 & 2 \\
\hline VII & $\mathrm{Sc}-A T F 2$ & Se- $A T F 2$ & 1 & 1 & 2 & 1 & 2 & 2 \\
\hline VIII & Sc- $B A T 1$ & Se- $A T F 1$ & 1 & 1 & 2 & 1 & 2 & 2 \\
\hline IX & & & 1 & 1 & 2 & 1 & 2 & 2 \\
\hline$X$ & & & 1 & 1 & 2 & 1 & 2 & 1 \\
\hline XI & & & 1 & 1 & 2 & 1 & 2 & 2 \\
\hline XII & & & 1 & 1 & 2 & 1 & 2 & 2 \\
\hline XIII & & & 1 & 1 & 2 & 1 & 2 & 2 \\
\hline XIV & & & 1 & 1 & 2 & 1 & 2 & 2 \\
\hline XV & $\mathrm{Sc}-A T F 1$ & Se- $B A T 1$ & 1 & 1 & 2 & 1 & 2 & 2 \\
\hline XVI & Sc-EEB1 & $\mathrm{Se}-E E B 1$ & 1 & 1 & 2 & 1 & 2 & 2 \\
\hline
\end{tabular}

Bold values depict chromosomes containing genes which have been reported to contribute to ester formation and that here were monitored with transcriptional analysis (Lilly et al. 2006; Saerens et al. 2006, 2008; Verstrepen et al. 2003; Zhang et al. 2013)

Scer, S. cerevisiae; Seub, S. eubayanus

\section{Fermentations in 15 and $25^{\circ} \mathrm{P}$ wort}

The wort fermentations revealed that an increased ploidy level in the hybrids was associated with improved fermentation performance. In the $15^{\circ} \mathrm{P}$ wort, all three hybrid strains fermented faster than the parent strains throughout the fermentation and had a higher alcohol content when this was measured after 15 days (Fig. 1a and Table 2). In the $25^{\circ} \mathrm{P}$ wort, only the allotriploid Hybrid B3 and allotetraploid Hybrid C4 were able to ferment faster than both parent strains (Fig. 1c and Table 2). These also had higher alcohol contents when measured after 23 days of fermentation. While the allodiploid Hybrid A2 fermented more poorly than the $S$. cerevisiae A81062 strain, it did ferment better than S. eubayanus C12902 strain. Comparing the hybrid strains, the Hybrid C4 fermented the fastest, followed by Hybrid B3 and finally the Hybrid A2 in both the $15^{\circ} \mathrm{P}$ and $25^{\circ} \mathrm{P}$ wort. The highest amount of suspended biomass (measured as dry mass) during fermentation was observed for Hybrid A2 in both the 15 and $25^{\circ} \mathrm{P}$ wort (Fig. 1b, d). High amounts of suspended biomass were also observed in the $S$. eubayanus $\mathrm{C} 12902$ fermentations at $15^{\circ} \mathrm{P}$, but growth was retarded in the harsher conditions of the $25^{\circ} \mathrm{P}$ wort. Hybrid B3, Hybrid C4, and the S. cerevisiae parent strain showed lower amounts of suspended biomass during fermentation, presumably as a result of their higher flocculation abilities (Table 2). The $S$. eubayanus parent strain showed a rapid drop in suspended biomass at the end of the fermentation in the $15^{\circ} \mathrm{P}$ wort despite its low flocculation ability. The beer $\mathrm{pH}$ also showed considerable variation (Table 2).

The differences in fermentation rate among the hybrid strains and the parent strains can partly be explained by their sugar consumption during fermentation. In the $15^{\circ} \mathrm{P}$ wort, the allotetraploid Hybrid C4 was the strain that used maltose and maltotriose fastest in the first half of fermentation (Fig. 2a, b). The allotriploid Hybrid B3 and allodiploid Hybrid A2 consumed maltotriose at a similar rate throughout fermentation, but the overall fermentation rate of Hybrid B3 was faster as a result of more efficient maltose consumption. The S. cerevisiae A81062 parent strain consumed maltotriose at a similar rate to Hybrid B3 and Hybrid A2, but consumed maltose at a lower rate than all three hybrid strains and also the S. eubayanus C12902 parent strain in the latter half of fermentation. As was expected based on previous research (Gibson et al. 2013a; Krogerus et al. 2015a), the S. eubayanus parent strain was unable to consume maltotriose. No glucose or fructose was detected in any of the samples that were drawn during fermentation, suggesting these sugars were rapidly depleted from the wort. In the $25^{\circ} \mathrm{P}$ wort, similar trends were observed, with the strains fermenting the fastest also consuming maltose and maltotriose the fastest (Fig. 2c, d). Hybrid A2 and the $S$. eubayanus strain consumed maltose poorly in the $25^{\circ} \mathrm{P}$ wort, resulting in an overall low fermentation rate. 

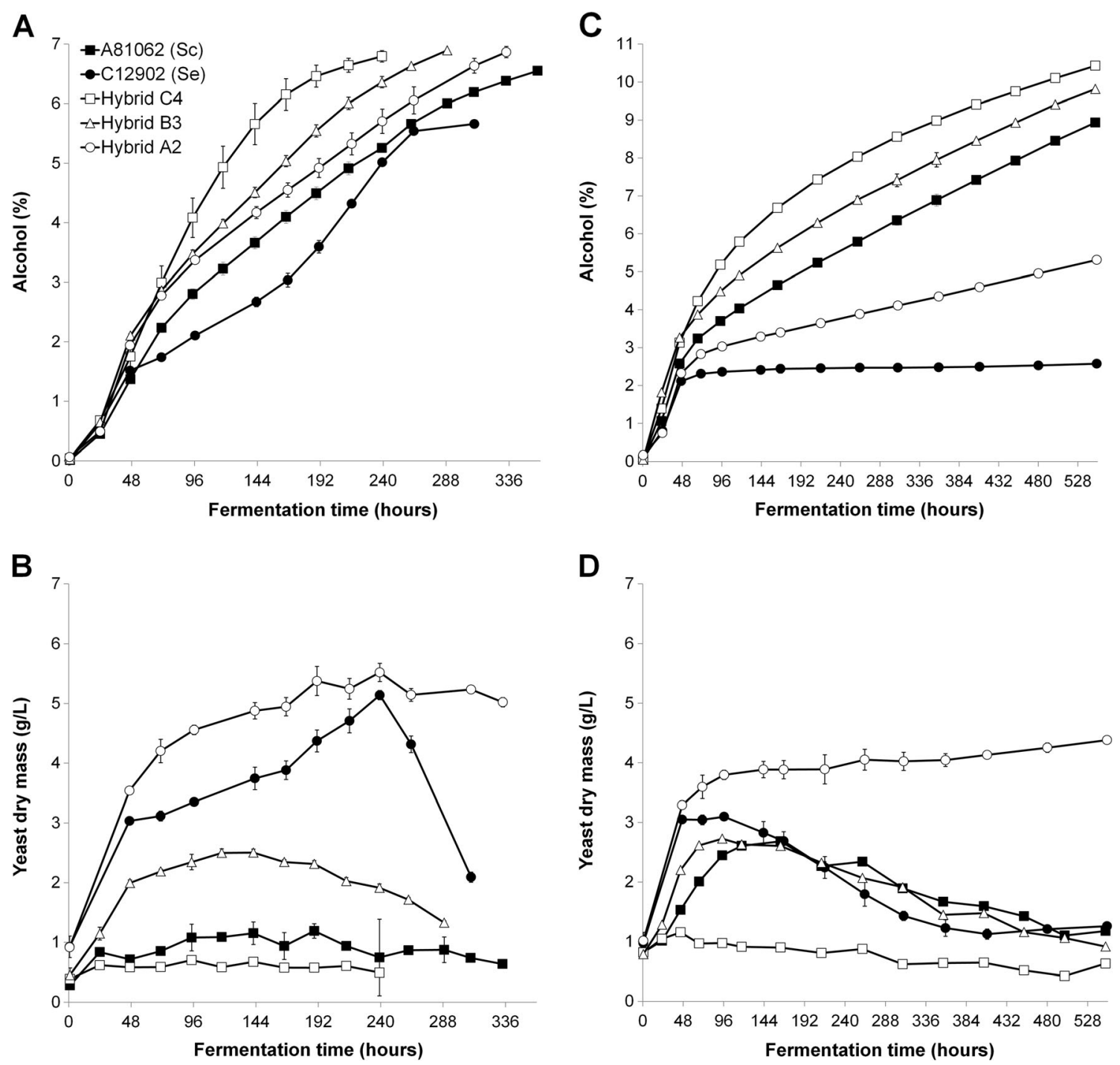

Fig. 1 The $\mathbf{a}, \mathbf{c}$ alcohol content ( $\% \mathrm{ABV}$ ) and $\mathbf{b}$, $\mathbf{d}$ suspended yeast dry mass $\left(\mathrm{g} \mathrm{L}^{-1}\right)$ of the 15 and $25^{\circ} \mathrm{P}$ worts fermented with the hybrid strains (white symbols) and parent strains (black symbols), respectively. Values

The viability measurements of the yeast harvested from the 15 and $25^{\circ} \mathrm{P}$ fermentations revealed that the $S$. cerevisiae A81062 parent strain, allotriploid Hybrid B3, and allodiploid Hybrid A2 were least affected by the intensified fermentation conditions in the $25^{\circ} \mathrm{P}$ wort (Table 2). Relatively low viabilities were measured for the allotetraploid Hybrid C4, probably because it had been exposed to higher concentrations of ethanol for a longer time as a result of its faster fermentation. The fermentation assay in worts supplemented with 5 and $10 \%$ ethanol revealed that the $S$. cerevisiae parent strain performed best in the presence of ethanol (Table 2). In the wort supplemented with $5 \%$ ethanol, Hybrid B3 and Hybrid C4 also nearly reached the same fermentation degree $(100 \%)$ as in the control wort, while the $\mathrm{C} 12902$ parent strain and Hybrid A 2 only reached approximately $60 \%$. In the wort supplemented with $10 \%$ ethanol, all strains performed poorly. However, are means from two independent fermentations and error bars where visible represent the standard deviation

the $S$. cerevisiae parent strain reached a slightly higher fermentation degree than the other strains (39 vs. $29 \%$ ).

\section{Aroma compounds in the beers}

The concentrations of yeast-derived aroma compounds in the beers showed notable variation (Figs. 3 and 4). For higher alcohols and esters, the trends between the different yeast strains remained similar throughout fermentation (Figs. S11 and S12 in the Supplementary material). Of the beers fermented from the $15^{\circ} \mathrm{P}$ wort, the allotetraploid Hybrid $\mathrm{C} 4$ produced the highest overall concentrations of flavor-active esters, showing a higher concentration of ethyl hexanoate than either parent and as high concentrations of 3-methylbutyl acetate, ethyl octanoate, and ethyl decanoate as the better parent. Comparing the parent strains, S. cerevisiae A81062 tended to 
Table 2 The parameters of the beers produced from the 15 and $25^{\circ} \mathrm{P}$ wort, the flocculation ability and viability of the parent and hybrid strains after fermentation in the 15 and $25^{\circ} \mathrm{P}$ wort, as well as the total amount of
$\mathrm{CO}_{2}$ lost during fermentation of a $10^{\circ} \mathrm{P}$ wort supplemented with 5 and $10 \%(v / v)$ ethanol in relation to the unsupplemented control wort

\begin{tabular}{|c|c|c|c|c|c|c|}
\hline \multicolumn{2}{|l|}{ Yeast strain } & \multirow{2}{*}{$\frac{\mathrm{A} 81062}{6.6( \pm 0.04)^{\mathrm{a}}}$} & \multirow{2}{*}{$\frac{\mathrm{C} 12902}{5.7( \pm 0.01)^{\mathrm{b}}}$} & \multirow{2}{*}{$\begin{array}{l}\text { Hybrid C4 } \\
6.8( \pm 0.10)^{\mathrm{a}}\end{array}$} & \multirow{2}{*}{$\frac{\text { Hybrid B3 }}{6.9( \pm 0.09)^{\mathrm{a}}}$} & \multirow{2}{*}{$\frac{\text { Hybrid A2 }}{6.9( \pm 0.10)^{\mathrm{a}}}$} \\
\hline $15^{\circ} \mathrm{P}$ & Alcohol $(\% v / v)$ & & & & & \\
\hline & Attenuation (\%) & $78( \pm 0.2)^{\mathrm{a}}$ & $68( \pm 0.01)^{\mathrm{b}}$ & $80( \pm 1.0)^{\mathrm{a}}$ & $82( \pm 1.0)^{\mathrm{a}}$ & $82( \pm 3.6)^{\mathrm{a}}$ \\
\hline & Maltose $\left(\mathrm{g} \mathrm{L}^{-1}\right)$ & $15.8( \pm 0.5)^{\mathrm{a}}$ & $4.0( \pm 0.8)^{\mathrm{b}}$ & $9.0( \pm 0.6)^{\mathrm{c}}$ & $4.8( \pm 0.7)^{\mathrm{b}}$ & $11.0( \pm 2.2)^{\mathrm{c}}$ \\
\hline & Maltotriose $\left(\mathrm{g} \mathrm{L}^{-1}\right)$ & $6.0( \pm 0.02)^{\mathrm{a}}$ & $25.9( \pm 0.6)^{\mathrm{b}}$ & $7.2( \pm 0.2)^{\mathrm{c}}$ & $8.5( \pm 0.3)^{\mathrm{d}}$ & $6.6( \pm 0.1)^{\mathrm{a}, \mathrm{c}}$ \\
\hline & $\mathrm{pH}$ & $4.44( \pm 0.01)^{\mathrm{a}}$ & $4.52( \pm 0.01)^{\mathrm{b}}$ & $4.68( \pm 0.01)^{\mathrm{c}}$ & $4.46( \pm 0.02)^{\mathrm{a}}$ & $4.10( \pm 0.01)^{\mathrm{d}}$ \\
\hline & Yeast viability (\%) & $89.9( \pm 1.0)^{\mathrm{a}}$ & $58.2( \pm 8.8)^{\mathrm{b}}$ & $60.7( \pm 3.0)^{\mathrm{b}}$ & $87.7( \pm 0.1)^{\mathrm{a}}$ & $98.5( \pm 0.0)^{\mathrm{a}}$ \\
\hline \multirow[t]{6}{*}{$25^{\circ} \mathrm{P}$} & Alcohol $(\% v / v)$ & $8.9( \pm 0.22)^{\mathrm{a}}$ & $2.6( \pm 0.01)^{\mathrm{b}}$ & $10.4( \pm 0.06)^{\mathrm{c}}$ & $9.8( \pm 0.25)^{\mathrm{c}}$ & $5.3( \pm 0.01)^{\mathrm{d}}$ \\
\hline & Attenuation (\%) & $58( \pm 1.6)^{\mathrm{a}}$ & $17( \pm 0.2)^{\mathrm{b}}$ & $67( \pm 0.6)^{\mathrm{c}}$ & $64( \pm 1.7)^{\mathrm{c}}$ & $32( \pm 0.3)^{\mathrm{d}}$ \\
\hline & Maltose $\left(\mathrm{g} \mathrm{L}^{-1}\right)$ & $63.7( \pm 2.6)^{\mathrm{a}}$ & $114.2( \pm 0.8)^{\mathrm{b}}$ & $39.8( \pm 1.0)^{\mathrm{c}}$ & $44.4( \pm 3.1)^{\mathrm{c}}$ & $104.4( \pm 3.7)^{\mathrm{d}}$ \\
\hline & Maltotriose $\left(\mathrm{g} \mathrm{L}^{-1}\right)$ & $11.0( \pm 0.9)^{\mathrm{a}}$ & $44.3( \pm 1.4)^{\mathrm{b}}$ & $11.9( \pm 0.2)^{\mathrm{a}, \mathrm{c}}$ & $13.7( \pm 1.6)^{\mathrm{c}}$ & $21.3( \pm 0.9)^{\mathrm{d}}$ \\
\hline & $\mathrm{pH}$ & $4.54( \pm 0.01)^{\mathrm{a}}$ & $4.71( \pm 0.01)^{\mathrm{b}}$ & $4.63( \pm 0.01)^{\mathrm{c}}$ & $4.56( \pm 0.01)^{\mathrm{a}}$ & $4.49( \pm 0.01)^{\mathrm{d}}$ \\
\hline & Yeast viability (\%) & $93.2( \pm 0.2)^{\mathrm{a}, \mathrm{b}}$ & $0.0( \pm 0.0)^{\mathrm{c}}$ & $5.9( \pm 3.3)^{\mathrm{c}}$ & $89( \pm 0.1)^{\mathrm{a}}$ & $96.8( \pm 0.1)^{\mathrm{b}}$ \\
\hline \multicolumn{2}{|c|}{ Flocculation ability (\%) } & $94.0( \pm 0.7)^{\mathrm{a}}$ & $2.6( \pm 1.7)^{\mathrm{b}}$ & $58.6( \pm 2.1)^{\mathrm{c}}$ & $73.1( \pm 5.2)^{\mathrm{d}}$ & $6.2( \pm 0.7)^{\mathrm{b}}$ \\
\hline \multicolumn{2}{|c|}{ Relative $\mathrm{CO}_{2}$ loss in wort with $5 \%(v / v)$ ethanol (\%) } & $105.5( \pm 5.2)^{\mathrm{a}}$ & $58.8( \pm 7.4)^{\mathrm{b}}$ & $94.5( \pm 2.6)^{\mathrm{a}}$ & $100.4( \pm 1.3)^{\mathrm{a}}$ & $59.3( \pm 7.3)^{\mathrm{b}}$ \\
\hline \multicolumn{2}{|c|}{ Relative $\mathrm{CO}_{2}$ loss in wort with $10 \%(v / v)$ ethanol $(\%)$} & $38.9( \pm 0.4)^{\mathrm{a}}$ & $27.3( \pm 1.3)^{\mathrm{b}}$ & $27.0( \pm 3.1)^{\mathrm{b}}$ & $29.4( \pm 3.6)^{\mathrm{b}}$ & $22.9( \pm 1.4)^{\mathrm{b}}$ \\
\hline
\end{tabular}

Values in the same row with different superscript letters differ significantly $(p<0.05)$. The flocculation abilities are means of three independent assays (standard deviation in parentheses), while beer parameters, viabilities, and relative $\mathrm{CO}_{2}$ loss are means from two independent fermentations (standard deviation in parentheses)

$N D$ not detected

produce higher concentrations of ethyl esters, while S. eubayanus C12902 tended to produce higher concentrations of acetate esters. This was reflected in the aroma profiles of the beers fermented with the hybrid strains and the contribution of the parent genomes in these hybrids. The beers fermented with the allotriploid Hybrid B3, containing proportionally more of the $S$. cerevisiae than the $S$. eubayanus parent genome, contained lower amounts of acetate esters (3methylbutyl acetate and ethyl acetate) than the beers fermented with the other two hybrids.

In the $25^{\circ} \mathrm{P}$ fermentations, the aroma compounds were at similar levels as in the $15^{\circ} \mathrm{P}$ fermentations (Fig. 4). As in the $15^{\circ} \mathrm{P}$ fermentations, when comparing the hybrid strains, Hybrid C4 produced the beer with the highest concentrations of flavor-active esters (higher concentrations of the acetate esters than either parent strain). Compared to Hybrid C4, Hybrid B3 produced similar concentrations of all ethyl esters, but significantly lower concentrations of 3-methylbutyl acetate and 2-phenylethyl acetate. As a result of the poor fermentations observed with the S. eubayanus parent and Hybrid A2, low amounts of flavor-active esters were also observed in the beers produced with these strains. The $S$. cerevisiae parent strain again produced high concentrations of ethyl esters.

The concentrations of diacetyl in the wort and beer also showed considerable variation among the parent and hybrid strains in both fermentations (Fig. 5). During the $15^{\circ} \mathrm{P}$ fermentation, the parent strains showed low levels of total diacetyl, with a maximum peak of around $200 \mu \mathrm{g} \mathrm{L}^{-1}$ for S. cerevisiae A81062. The highest diacetyl peaks, at around $900 \mu \mathrm{g} \mathrm{L}^{-1}$, were observed for Hybrid C4 and Hybrid A2. However, the diacetyl concentration in the beer fermented with Hybrid A2 was only $210 \mu \mathrm{g} \mathrm{L}^{-1}$, while it was $385 \mu \mathrm{g}$ $\mathrm{L}^{-1}$ for Hybrid C4. The diacetyl concentrations of Hybrid B3 were in between those of Hybrid C4 and the parents. During the $25^{\circ} \mathrm{P}$ fermentations, the highest diacetyl peak was again observed for Hybrid C4, while the lowest diacetyl levels were again observed for $S$. eubayanus. In contrast to the $15^{\circ} \mathrm{P}$ fermentation, relatively low concentrations of diacetyl were observed for Hybrid A2. These are most likely a result of the poor fermentation performance that was observed for this strain in the $25^{\circ} \mathrm{P}$ wort.

\section{Transcriptional analysis}

Transcriptional analysis was performed on both orthologues (S. cerevisiae- and S. eubayanus-derived) of five genes previously reported to contribute to ester formation (Lilly et al. 2006; Saerens et al. 2006, 2008; Verstrepen et al. 2003; Zhang et al. 2013): ATF1, ATF2, EHT1, EEB1, and BAT1 (Table 1). Yeast samples were taken from the $15^{\circ} \mathrm{P}$ fermentations at different time points. Positive correlations were observed both between the overall transcription levels and the deduced gene copy numbers, as well as the transcription levels of specific genes and corresponding esters. 

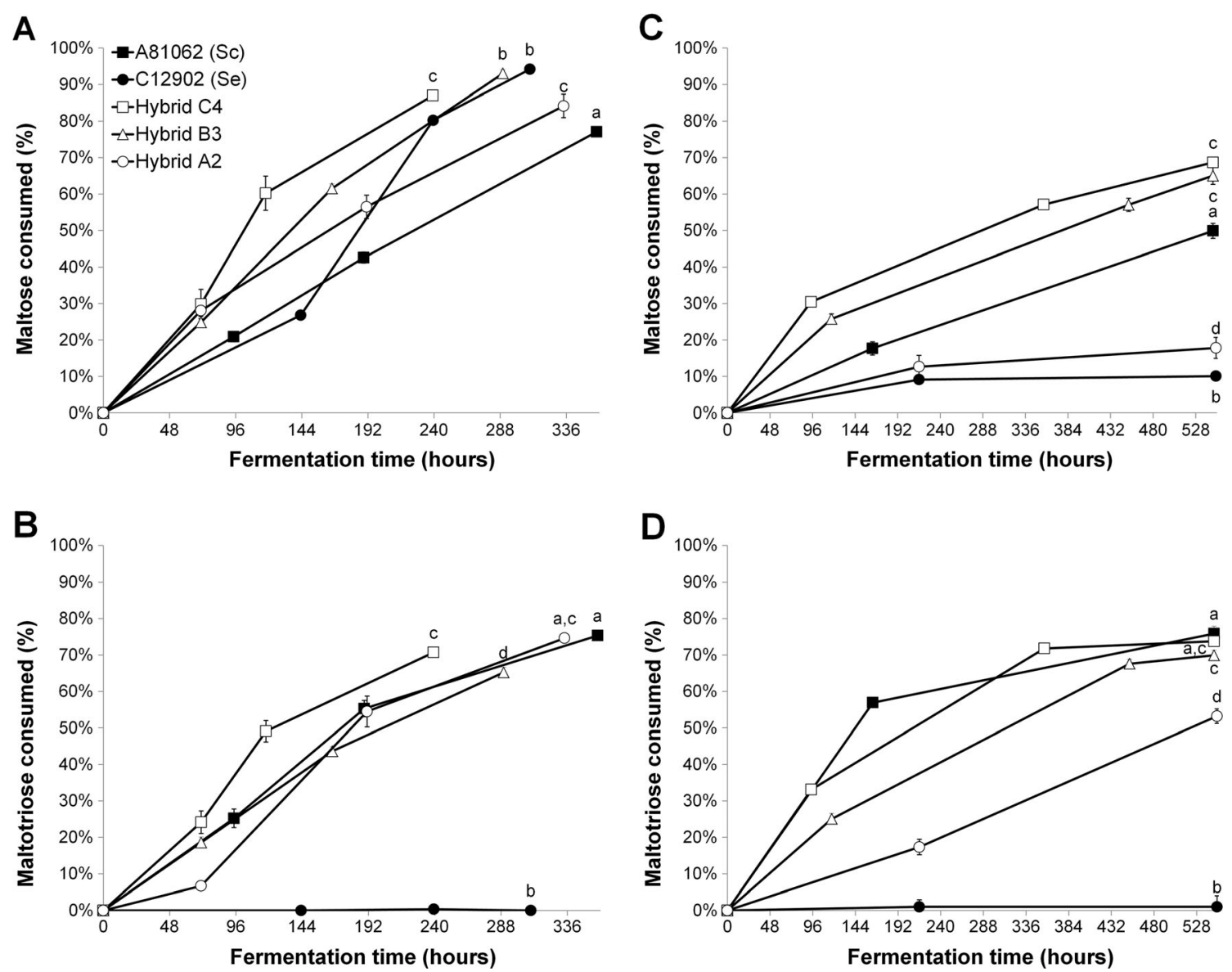

Fig. 2 The amount of a, $\mathbf{c}$ maltose ( $\%$ of concentration in original wort) and $\mathbf{b}, \mathbf{d}$ maltotriose ( $\%$ of concentration in original wort) consumed in the 15 and $25^{\circ} \mathrm{P}$ worts fermented with the hybrid strains (white symbols) and parent strains (black symbols), respectively. Values are means from

two independent fermentations and error bars where visible represent the standard deviation. Values with different letters above the final sampling point differ significantly $(p<0.05)$

Higher or equal transcription levels of both Sc-ATF1 and Se-ATF1 were observed for the allotetraploid Hybrid C4 during active fermentation compared to the parent strains, with up to 2.5-fold and 2-fold differences, respectively (Fig. 6). The allotriploid Hybrid B3 also showed higher or equal transcription levels of Sc-ATF1 compared to S. cerevisiae A81062, while the allodiploid Hybrid A2 showed up to 2-fold lower transcription levels. For Se-ATF1, both Hybrid B3 and Hybrid A2 showed approximately 2 -fold lower transcription levels at 33 and $60 \%$ attenuation compared to S. eubayanus $\mathrm{C} 12902$. Similar trends were observed for Sc-ATF2 and Se-ATF2, where the overall highest levels of transcription among the hybrids were observed with Hybrid C4.

For Sc-EHT1, the highest transcription levels were observed for the $S$. cerevisiae parent strain, which showed a 2fold difference at $33 \%$ apparent attenuation compared to Hybrid B3 and Hybrid C4. A signal was obtained with the Sc-EHT1 probe from the fermentations with the S. eubayanus parent strain, meaning that the probe was non-specific and cross-hybridized to something in the sample, possibly SeEHT1 mRNA. For Se-EHT1, the highest transcription levels

were observed with the S. eubayanus parent strain throughout the fermentation. Towards the end of fermentation, the transcription level observed for Hybrid $\mathrm{C} 4$ was similar to the S. eubayanus parent. The transcription of Sc-EEB1 was similar among the $S$. cerevisiae parent and all hybrid strains at $24 \mathrm{~h}$ and $33 \%$ apparent attenuation, with the exception of Hybrid A2 at $33 \%$ attenuation, where an approximately 2fold lower transcription level was observed. Towards the end of fermentation, a 2.5-fold higher transcription level was observed for Hybrid C4 and Hybrid B3 relative to the allodiploid. For Se-EEB1, similar transcription levels were observed for all hybrid strains during active fermentation.

The transcription levels of Sc-BATl followed similar patterns as Sc-EEB1, with little differences observed between the transcription levels of the $S$. cerevisiae, Hybrid $\mathrm{C} 4$, and Hybrid B3 in the beginning of fermentation, while transcription levels were around 1.5- to 2-fold higher in the hybrids towards the end of fermentation. The transcription level in the Hybrid A2 was up to 2.5-fold lower than the $S$. cerevisiae parent strain during active fermentation. For Se-BAT1, the transcription levels in the S. eubayanus parent, Hybrid B3, 


\begin{tabular}{|c|c|c|c|c|c|}
\hline$\left(\mathrm{mg} \mathrm{L}^{-1}\right)$ & Sc A81062 & Se C12902 & Hybrid C4 & Hybrid B3 & Hybrid A2 \\
\hline $\begin{array}{r}\text { Acetaldehyde } \\
\left(10 \mathrm{mg} \mathrm{L}^{-1}\right)\end{array}$ & $\begin{array}{c}21.31 \\
( \pm 1.48)\end{array}$ & $\begin{array}{c}8.34 \\
( \pm 0.57)\end{array}$ & $\begin{array}{l}30.20 \\
( \pm 2.80)\end{array}$ & ${ }_{( \pm 1.65)}^{15.34} d$ & $\begin{array}{c}4.99 \\
( \pm 0.30)\end{array}$ \\
\hline $\begin{array}{l}\text { 1-Propanol } \\
\left(800 \mathrm{mg} \mathrm{L}^{-1}\right)\end{array}$ & $\begin{array}{c}16.38 \\
( \pm 0.44)^{a}\end{array}$ & $\begin{array}{c}13.76 \\
( \pm 0.96)\end{array}$ & ${ }_{( \pm 0.56)}^{16.95}$ a,c & $\begin{array}{c}18.08 \\
( \pm 0.36)\end{array}$ & ${ }_{( \pm 1.13)}^{25.34} d$ \\
\hline $\begin{array}{r}\text { 2-Methylpropanol } \\
\left(200 \mathrm{mg} \mathrm{L}^{-1}\right)\end{array}$ & $\begin{array}{c}11.40 \\
( \pm 0.51)\end{array}$ & $\begin{array}{l}31.05 \\
( \pm 1.67)\end{array}$ & $\begin{array}{l}24.95 \\
( \pm 1.02)\end{array}$ & $\begin{array}{l}21.45 \\
( \pm 0.50)\end{array}$ & $\begin{array}{c}36.54 \\
( \pm 1.36)\end{array}$ \\
\hline $\begin{array}{r}\text { 2-Methylbutanol } \\
\left(65 \mathrm{mg} \mathrm{L}^{-1}\right)\end{array}$ & $\begin{array}{c}17.59 \\
( \pm 0.64)\end{array}$ & $\begin{array}{c}28.09 \\
( \pm 1.40)\end{array}$ & $\begin{array}{l}32.86 \\
( \pm 1.01)\end{array}$ & $\begin{array}{c}28.41 \\
( \pm 0.60)\end{array}$ & $\begin{array}{l}32.44 \\
( \pm 1.56)\end{array}$ \\
\hline $\begin{array}{r}\text { 3-Methylbutanol } \\
\left(70 \mathrm{mg} \mathrm{L}^{-1}\right)\end{array}$ & $\begin{array}{c}21.09 \\
( \pm 0.99)^{a}\end{array}$ & $\begin{array}{l}73.27 \\
( \pm 3.44)\end{array}$ & $\begin{array}{l}54.05 \\
( \pm 2.10)\end{array}$ & $\begin{array}{l}45.62 \\
( \pm 1.05)\end{array}$ & $\begin{array}{c}89.42 \\
( \pm 3.81)\end{array}$ \\
\hline $\begin{array}{r}\text { 3-Methylbutyl acetate } \\
\left(1.2 \mathrm{mg} \mathrm{L}^{-1}\right)\end{array}$ & $\begin{array}{c}0.62 \\
( \pm 0.06)^{a}\end{array}$ & $\begin{array}{c}2.60 \\
( \pm 0.15)\end{array}$ & $\begin{array}{c}2.51 \\
( \pm 0.17)^{b}\end{array}$ & $\begin{array}{c}1.45 \\
( \pm 0.12)\end{array}$ & $\begin{array}{c}1.75 \\
( \pm 0.11)\end{array}$ \\
\hline $\begin{array}{r}\text { 2-Phenylethyl acetate } \\
\left(0.3 \mathrm{mg} \mathrm{L}^{-1}\right)\end{array}$ & $\begin{array}{c}0.15 \\
( \pm 0.02)^{a}\end{array}$ & $\begin{array}{c}1.56 \\
( \pm 0.16)\end{array}$ & $\begin{array}{c}0.89 \\
( \pm 0.03)^{c}\end{array}$ & $\begin{array}{c}0.24 \\
( \pm 0.01)^{a}\end{array}$ & $\begin{array}{c}0.24 \\
( \pm 0.03)^{a}\end{array}$ \\
\hline $\begin{array}{l}\text { Ethyl acetate } \\
\left(30 \mathrm{mg} \mathrm{L}^{-1}\right)\end{array}$ & $\begin{array}{c}29.30 \\
( \pm 2.42)\end{array}$ & $\begin{array}{c}30.83 \\
( \pm 2.03)^{a}\end{array}$ & $\begin{array}{c}32.90 \\
( \pm 2.08)^{a}\end{array}$ & $\begin{array}{l}41.42 \\
( \pm 2.72)\end{array}$ & $\begin{array}{l}60.15 \\
( \pm 2.72)^{c}\end{array}$ \\
\hline $\begin{array}{r}\text { Ethyl hexanoate } \\
\left(0.21 \mathrm{mg} \mathrm{L}^{-1}\right)\end{array}$ & $\begin{array}{c}0.40 \\
( \pm 0.02)\end{array}$ & $\begin{array}{c}0.10 \\
( \pm 0.01)\end{array}$ & $\begin{array}{c}0.48 \\
( \pm 0.03)\end{array}$ & $\begin{array}{c}0.42 \\
( \pm 0.05)^{a}\end{array}$ & $\begin{array}{c}0.38 \\
( \pm 0.02)\end{array}$ \\
\hline $\begin{array}{r}\text { Ethyl octanoate } \\
\left(0.9 \mathrm{mg} \mathrm{L}^{-1}\right)\end{array}$ & $\begin{array}{c}0.36 \\
( \pm 0.18)\end{array}$ & $\begin{array}{c}0.20 \\
( \pm 0.04)\end{array}$ & $\begin{array}{c}0.44 \\
( \pm 0.12)\end{array}$ & $\begin{array}{c}0.22 \\
( \pm 0.08)\end{array}$ & $\begin{array}{c}0.17 \\
( \pm 0.04)\end{array}$ \\
\hline $\begin{array}{r}\text { Ethyl decanoate } \\
\left(1.5 \mathrm{mg} \mathrm{L}^{-1}\right)\end{array}$ & $\begin{array}{c}0.04 \\
( \pm 0.02)^{a}\end{array}$ & $\begin{array}{c}0.12 \\
( \pm 0.02)\end{array}$ & $\begin{array}{c}0.16 \\
( \pm 0.03)^{b}\end{array}$ & $\begin{array}{c}0.04 \\
( \pm 0.01)^{a}\end{array}$ & $\begin{array}{c}0.07 \\
( \pm 0.02)^{a}\end{array}$ \\
\hline
\end{tabular}

Fig. 3 The concentrations ( $\mathrm{mg} \mathrm{L}^{-1}$ ) of aroma compounds (rows) in the beers fermented from the $15^{\circ} \mathrm{P}$ wort with the hybrid and parent strains (columns). The heat map was generated based on the z-scores (blue and red indicate low and high values, respectively). The values in parentheses under the compound names represent the flavor threshold (Meilgaard
1982). Values are means from two independent fermentations (standard deviation in parentheses) and they have not been normalized to the ethanol concentration. Values in the same row with different superscript letters $(a-e)$ differ significantly $(p<0.05)$

larger positive influence than the S. cerevisiae-derived counterparts. For the concentrations of ethyl hexanoate, the expression of the S. cerevisiae-derived orthologues of EHT1 and $E E B 1$ tended to have a larger positive influence compared to the $S$. eubayanus-derived orthologues. correlation of 0.88 ( $p$ value lower than 0.0001 ) was obtained between the normalized average transcription levels of each orthologous gene in each strain (normalized to zero mean and unit variance) and the deduced gene copy numbers in Table 1 . Linear regressions (adjusted $R^{2}$ ranged from 0.68 to 0.89 , and all $F$ test $p$ values were below 0.008 ; see Table $\mathrm{S} 4$ and $\mathrm{S} 5$ in Supplementary material) only revealed significant correlations between the maximum transcription levels of ATF1 and $A T F 2$ and the concentrations 3-methylbutyl acetate and 2-phenylethyl acetate, as well as the maximum transcription levels of EHT1 and EEB1 and the concentrations of ethyl hexanoate (Table 3). For the concentrations of 3-methylbutyl acetate and 2-phenylethyl acetate, the expression of the S. eubayanus-derived orthologues of ATF1 and ATF2 had a
While extensive research has been conducted on the development of brewing yeast through genetic engineering techniques in the past decades, the industrial use of genetically modified yeast is still not common as a result of regulations and public opinion (Cebollero et al. 2007; Stewart et al. 2013; Twardowski and Malyska 2015). Hence, there is a still a demand for developing and improving alternative, non-GM, strain-development techniques. One such technique is interspecific hybridization, which was used here to generate three lager yeast hybrids with varying DNA content. The purpose of

\section{Discussion}




\begin{tabular}{|c|c|c|c|c|c|}
\hline$\left(\mathrm{mg} \mathrm{L}^{-1}\right)$ & Sc A81062 & Se C12902 & Hybrid C4 & Hybrid B3 & Hybrid A2 \\
\hline $\begin{array}{r}\text { Acetaldehyde } \\
\left(10 \mathrm{mg} \mathrm{L}^{-1}\right)\end{array}$ & $\begin{array}{c}14.24 \\
( \pm 1.33)^{a}\end{array}$ & $\begin{array}{c}20.86 \\
( \pm 2.08)\end{array}$ & $\begin{array}{c}31.94 \\
( \pm 1.21)\end{array}$ & $\begin{array}{c}16.23 \\
( \pm 1.63)^{a}\end{array}$ & $\begin{array}{c}5.19 \\
( \pm 0.31)\end{array}$ \\
\hline $\begin{array}{r}\text { 1-Propanol } \\
\left(800 \mathrm{mg} \mathrm{L}^{-1}\right)\end{array}$ & $\begin{array}{l}30.16 \\
( \pm 1.15)^{a}\end{array}$ & $\begin{array}{c}6.67 \\
( \pm 0.43)\end{array}$ & $\begin{array}{l}34.85 \\
( \pm 1.17)\end{array}$ & $\begin{array}{c}29.02 \\
( \pm 1.94)^{a}\end{array}$ & $\begin{array}{c}17.90 \\
( \pm 1.33)\end{array}$ \\
\hline $\begin{array}{r}\text { 2-Methylpropanol } \\
\left(200 \mathrm{mg} \mathrm{L}^{-1}\right)\end{array}$ & $\begin{array}{c}16.59 \\
( \pm 0.88)\end{array}$ & $\begin{array}{c}14.01 \\
( \pm 0.64)\end{array}$ & $\begin{array}{l}51.34 \\
( \pm 1.16)\end{array}$ & $\begin{array}{l}35.59 \\
( \pm 1.97)\end{array}$ & $\begin{array}{c}23.96 \\
( \pm 0.88)\end{array}$ \\
\hline $\begin{array}{r}\text { 2-Methylbutanol } \\
\quad\left(65 \mathrm{mg} \mathrm{L}^{-1}\right)\end{array}$ & $\begin{array}{c}13.31 \\
( \pm 0.62)\end{array}$ & $\begin{array}{l}11.39 \\
( \pm 0.49)\end{array}$ & $\begin{array}{l}42.67 \\
( \pm 0.79)\end{array}$ & $\begin{array}{l}31.34 \\
( \pm 1.63)\end{array}$ & $\begin{array}{c}20.72 \\
( \pm 0.59)\end{array}$ \\
\hline $\begin{array}{r}\text { 3-Methylbutanol } \\
\left(70 \mathrm{mg} \mathrm{L}^{-1}\right)\end{array}$ & $\begin{array}{c}36.00 \\
( \pm 1.31)\end{array}$ & $\begin{array}{c}36.30 \\
( \pm 1.37)\end{array}$ & $\begin{array}{c}81.81 \\
( \pm 1.37)\end{array}$ & $\begin{array}{l}57.43 \\
( \pm 2.62)\end{array}$ & $\begin{array}{l}57.02 \\
( \pm 1.69)\end{array}$ \\
\hline $\begin{array}{r}\text { 3-Methylbutyl acetate } \\
\left(1.2 \mathrm{mg} \mathrm{L}^{-1}\right)\end{array}$ & $\begin{array}{c}0.84 \\
( \pm 0.07)^{a}\end{array}$ & $\begin{array}{c}0.49 \\
( \pm 0.04)\end{array}$ & $\begin{array}{c}2.14 \\
( \pm 0.10)\end{array}$ & $\begin{array}{c}1.51 \\
( \pm 0.12)\end{array}$ & $\begin{array}{c}1.14 \\
( \pm 0.11)\end{array}$ \\
\hline $\begin{array}{r}\text { 2-Phenylethyl acetate } \\
\left(0.3 \mathrm{mg} \mathrm{L}^{-1}\right)\end{array}$ & ND & $\begin{array}{c}0.34 \\
( \pm 0.02)\end{array}$ & $\begin{array}{c}0.39 \\
( \pm 0.03)^{c}\end{array}$ & $\underset{( \pm 0.01)}{0.15} d$ & ND \\
\hline $\begin{array}{r}\text { Ethyl acetate } \\
\left(30 \mathrm{mg} \mathrm{L}^{-1}\right)\end{array}$ & $\begin{array}{c}55.40 \\
( \pm 4.60)^{a}\end{array}$ & $\begin{array}{c}7.49 \\
( \pm 0.53)\end{array}$ & $\begin{array}{l}62.84 \\
( \pm 1.62)\end{array}$ & $\begin{array}{l}78.20 \\
( \pm 4.16)\end{array}$ & $\begin{array}{l}44.24 \\
( \pm 1.67)\end{array}$ \\
\hline $\begin{array}{r}\text { Ethyl hexanoate } \\
\left(0.21 \mathrm{mg} \mathrm{L}^{-1}\right)\end{array}$ & $\begin{array}{c}0.58 \\
( \pm 0.06)^{a}\end{array}$ & $\begin{array}{c}0.06 \\
( \pm 0.01)\end{array}$ & $\begin{array}{c}0.33 \\
( \pm 0.03)^{c}\end{array}$ & $\begin{array}{c}0.36 \\
( \pm 0.05)\end{array}$ & ${ }_{( \pm 0.02)}^{0.21} d$ \\
\hline $\begin{array}{l}\text { Ethyl octanoate } \\
\left(0.9 \mathrm{mg} \mathrm{L}^{-1}\right)\end{array}$ & $\begin{array}{c}0.57 \\
( \pm 0.15)^{a}\end{array}$ & $\begin{array}{c}0.41 \\
( \pm 0.06)\end{array}$ & $\begin{array}{c}0.24 \\
( \pm 0.03)\end{array}$ & $\begin{array}{c}0.15 \\
( \pm 0.02)\end{array}$ & $\begin{array}{c}0.14 \\
( \pm 0.02)\end{array}$ \\
\hline $\begin{array}{r}\text { Ethyl decanoate } \\
\left(1.5 \mathrm{mg} \mathrm{L}^{-1}\right)\end{array}$ & $\begin{array}{c}0.11 \\
( \pm 0.04)^{a}\end{array}$ & $\begin{array}{c}0.21 \\
( \pm 0.02)\end{array}$ & $\begin{array}{c}0.12 \\
( \pm 0.01)^{a}\end{array}$ & $\begin{array}{c}0.04 \\
( \pm 0.01)^{c}\end{array}$ & $\begin{array}{c}0.05 \\
( \pm 0.01)^{c}\end{array}$ \\
\hline
\end{tabular}

Fig. 4 The concentrations ( $\mathrm{mg} \mathrm{L}^{-1}$ ) of aroma compounds (rows) in the beers fermented from the $25^{\circ} \mathrm{P}$ wort with the hybrid and parent strains (columns). The heat map was generated based on the z-scores (blue and red indicate low and high values, respectively). The values in parentheses under the compound names represent the flavor threshold (Meilgaard
1982). Values are means from two independent fermentations (standard deviation in parentheses) and they have not been normalized to the ethanol concentration. Values in the same row with different superscript letters $(a-e)$ differ significantly $(p<0.05)$

fermentations can partially be explained by the superior ability of the hybrid strains to take up and consume maltose and maltotriose from the wort. In brewing strains, the uptake of these sugars is carried out by various transmembrane transporters, such as Agt1, Malx1, and Mtt1 (Cousseau et al. 2013; Dietvorst et al. 2005; Vidgren et al. 2005, 2009). It has been shown that the activities of these transporters are dependent on temperature, origin, and membrane lipid composition (Guimarães et al. 2006; Vidgren et al. 2010, 2014), and that S. eubayanus-derived transporters in lager yeast tend to retain higher activities at lower temperatures compared to the S. cerevisiae-derived counterparts. Here, the hybrid strains, especially the allotetraploid Hybrid $\mathrm{C} 4$ and allotriploid Hybrid B3, were able to combine the efficient maltotriose use from the $S$. cerevisiae parent and the efficient maltose use from the $S$. eubayanus parent.

While all hybrid strains outperformed the parent strains in the $15^{\circ} \mathrm{P}$ wort, it was only the allotriploid Hybrid B3 and allotetraploid Hybrid $\mathrm{C} 4$ that did so in the $25^{\circ} \mathrm{P}$ very high vigor that was observed during both the 15 and $25{ }^{\circ} \mathrm{P}$ 

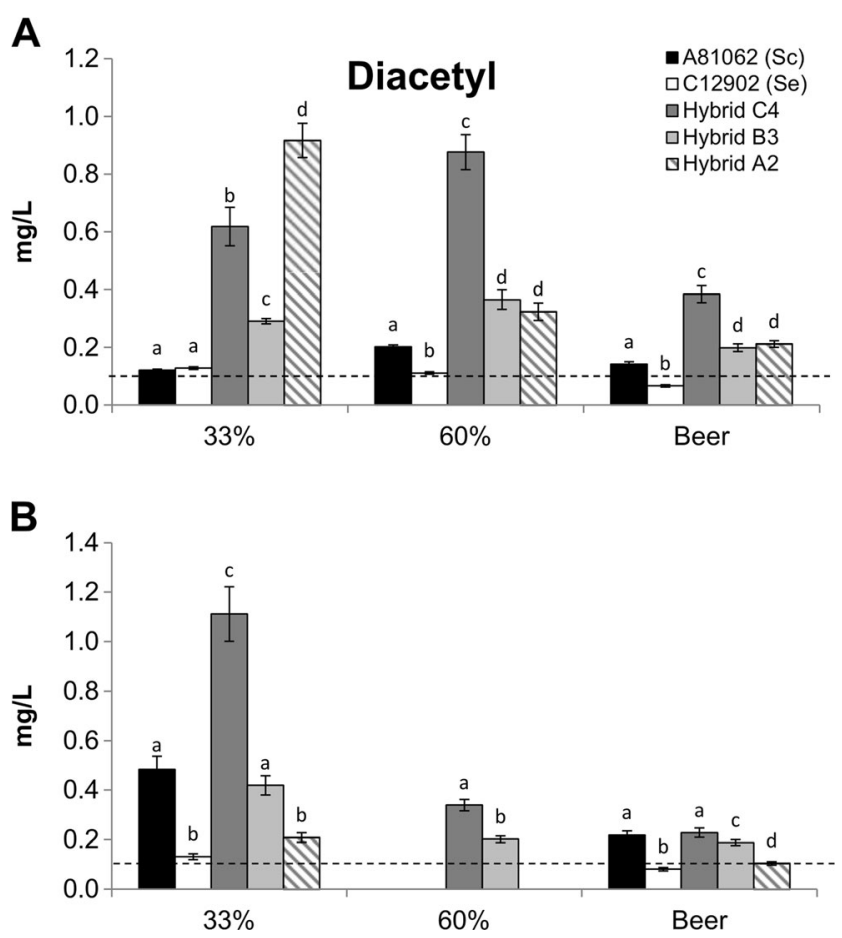

Fig. 5 The concentrations of diacetyl in the wort (33 and $60 \%$ attenuation) and beers fermented from the a $15{ }^{\circ} \mathrm{P}$ and $\mathbf{b} 25^{\circ} \mathrm{P}$ wort with the hybrid and parent strains $\left(\mathrm{mg} \mathrm{L}^{-1}\right)$. Where visible, the dashed line represents the typical flavor threshold (Meilgaard 1982). Values are means from two independent fermentations and error bars where visible represent the standard deviation. Values from the same sampling point with different letters $(a-d)$ above the bars differ significantly $(p<0.05)$

gravity wort. These hybrids also showed a higher ethanol tolerance than the allodiploid Hybrid A2. Fermentation of very high gravity wort is limited by various environmental stresses, such as high osmotic pressure, high alcohol concentrations, and nutrient starvation (Blieck et al. 2007; Gibson et al. 2007; Gibson 2011). Our observations would suggest that polyploid hybrids possess increased stress tolerance, possibly as a result of increased gene dosage and positive selection of specific gene products, masking of deleterious recessive mutations, transcriptome changes, and even increased cell size (Schoenfelder and Fox 2015; Storchova 2014). Mechanisms affecting the ethanol and stress tolerance in yeast include the lipid composition of the plasma membrane (Henderson and Block 2014), intracellular trehalose concentrations (Bandara et al. 2009), and expression of general stress response genes (Sadeh et al. 2011). Studies have also shown that flocculating cells tend to be more tolerant towards ethanol, which is reflected in our results as well (Smukalla et al. 2008). It is unclear what factors contribute to the differences in ethanol and stress tolerance observed here between the hybrid and their parent strains, and these should be addressed in future work. The poor performance of the allodiploid Hybrid A2 in the $25^{\circ} \mathrm{P}$ wort observed here is most likely coincidental, as previous studies have reported the generation of hybrid strains with superior ethanol production and tolerance through mass mating (Snoek et al. 2015; Zheng et al. 2011). On the other hand, Mertens et al. (2015) also observed poor fermentation performance with allodiploid yeast hybrids compared to allotriploid hybrids in pilot-scale wort fermentations. However, this may rather be associated with the performance of the parent strains. A more general observation could have been obtained by including a larger number of hybrids in the study.

Brewing yeast strain development is not only driven by a demand for faster and more tolerant brewing yeasts. The demand for brewing yeasts that produce novel and distinct flavor profiles has also increased in the past decade, as the beer industry has been driven by an increasing demand for craft and specialty beers that are rich in aroma (Aquilani et al. 2015). Our results suggest that it is not only possible to generate hybrid lager yeasts with higher aroma production compared to the parent strains but that the aroma profile of these hybrids can also be directed depending on the mating method and the DNA content and inheritance of the hybrids. Recent studies on other yeast hybrids have also revealed the possibility to either increase aroma production or achieve midparent values in hybrids (Bellon et al. 2011, 2013; da Silva et al. 2015; Gamero et al. 2013; Krogerus et al. 2015a; Mertens et al. 2015; Steensels et al. 2014a). Here, a positive correlation was observed both between transcription levels and gene copy numbers as well as the maximum transcription levels of several genes and the concentrations of corresponding aroma compounds in the beers. Hence, the increase in aroma production in the hybrid strains compared to the parents can be partly explained by the combined expression of both orthologous genes inherited from the parent strains. Previous studies on the expression of genes related to the synthesis of aroma compounds in newly formed interspecific yeast hybrids are limited. Nevertheless, studies on natural hybrids have revealed both that there is a positive correlation between the formation of aroma compounds and the expression level of several genes involved in their synthesis (e.g., $A T F 1, A T F 2$, and $B A T 1$ ), and that orthologues of these genes in lager yeast are differentially transcribed during fermentation (He et al. 2014; Procopio et al. 2014; Saerens et al. 2008). Studies have shown that gene expression patterns in yeast hybrids are affected by environmental factors such as temperature ( $\mathrm{Li}$ et al. 2012; Tirosh et al. 2009), which may also affect the contribution from the parental genomes in lager yeasts.

Aside from the observed link between ester concentrations and transcript levels, the results from transcriptional analysis also suggest that the functionality of the orthologous gene products differ. Four-fold higher concentrations of 3methylbutyl acetate were observed in the $15^{\circ} \mathrm{P}$ beer fermented with the $S$. eubayanus parent strain compared to $S$. cerevisiae parent strain, despite quite similar expression levels of the respective orthologous genes of $A T F 1$ and $A T F 2$. Furthermore, similar concentrations of 3-methylbutyl acetate 

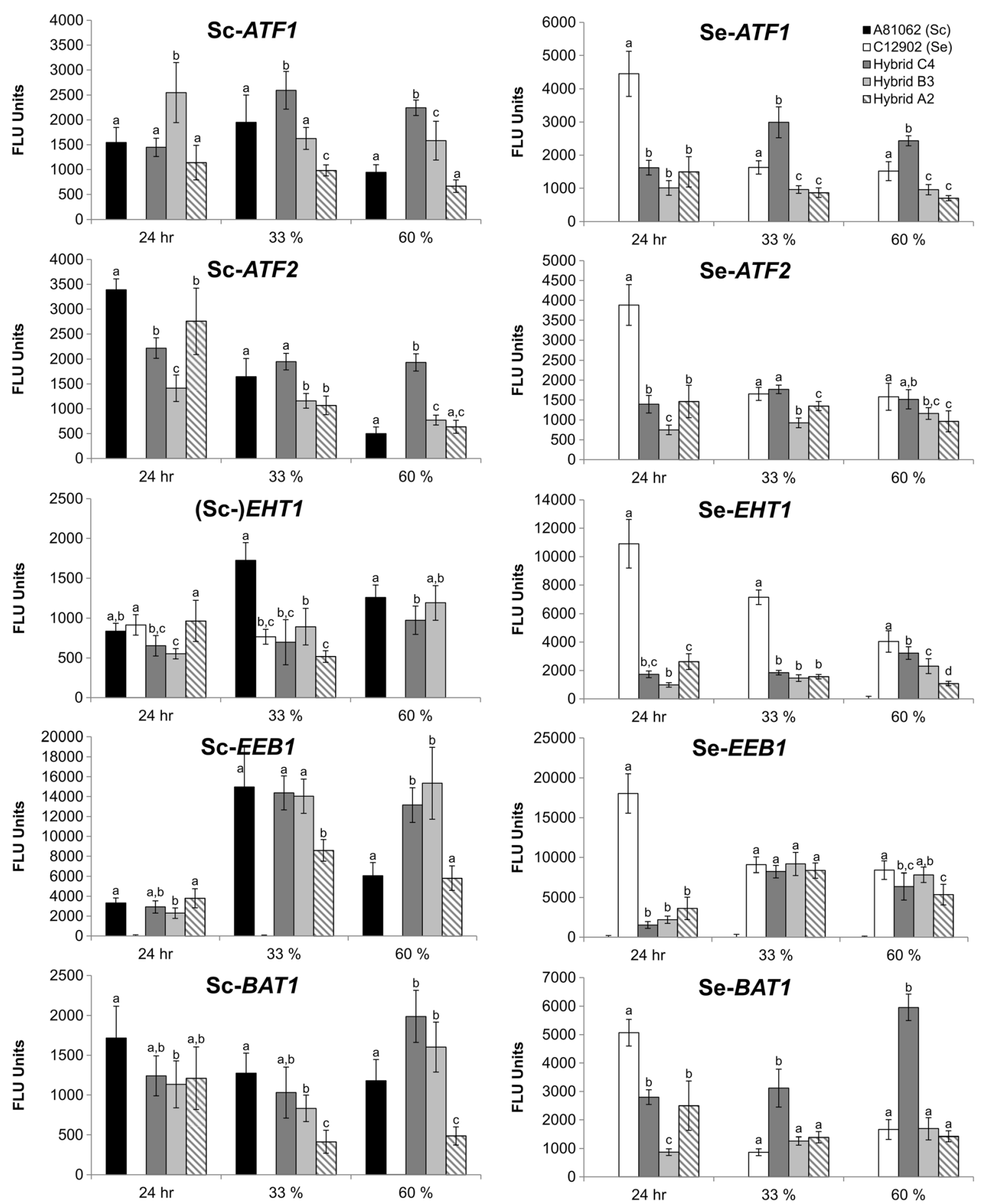

Fig. 6 Transcription of $S$. cerevisiae $(S c)$ and $S$. eubayanus $(S e)$ orthologues of genes responsible for ester formation during fermentation of the $15^{\circ} \mathrm{P}$ wort with the hybrid and parent strains. Samples were taken at $24 \mathrm{~h}, 33 \%$ attenuation, and $60 \%$ attenuation.

were measured in the beers produced with the $S$. eubayanus parent and the allotetraploid Hybrid $\mathrm{C} 4$, as well as the allotriploid Hybrid B3 and allodiploid Hybrid A2, despite the fact that higher concentrations of the precursor 3-methyl butanol were measured in the beers produced with the S. eubayanus parent and Hybrid A2. This suggests that the
Values are means from two independent fermentations and error bars where visible represent the standard deviation. Values from the same sampling point with different letters $(a-d)$ above the bars differ significantly $(p<0.05)$

differences in ester concentrations were not limited by precursor availability. Surprisingly, relatively high concentrations of ethyl esters were observed in the beer fermented with the allodiploid Hybrid A2 despite it showing low expression levels of Sc-EHT1. These results, together with the multiple linear regression models, would suggest that the expression of 
Table 3 The $\beta$ coefficients of the multiple linear regressions between maximum transcription levels and the beer concentrations of various aroma compounds

\begin{tabular}{lllll}
\hline Gene & 3-Methylbutyl acetate & 2-Phenylethyl acetate & Gene & Ethyl hexanoate \\
\hline Sc- $A T F 1$ & NS & NS & Sc- $E H T 1$ & NS \\
Se- $A T F 1$ & $4.8 \times 10^{-4}$ & $3.1 \times 10^{-4}$ & Se- $E H T 1$ & $-3.8 \times 10^{-5}$ \\
Sc- $A T F 2$ & NS & NS & Sc-EEB1 & $1.6 \times 10^{-5}$ \\
Se- $A T F 2$ & $5.8 \times 10^{-4}$ & $3.7 \times 10^{-4}$ & Se-EEB1 & NS \\
\hline
\end{tabular}

All coefficient values are significant $(p<0.05)$ and show a correlation between the transcription of that gene and the beer concentration of that aroma compound

$N S$ not significant $(p>0.05)$
Sc-EEB1 has a stronger influence on the formation of ethyl esters, especially ethyl hexanoate, during fermentation, which is in agreement with previous studies (Saerens et al. 2008).

While the hybrid strains produced higher amounts of desirable aroma-active esters, they also produced higher concentrations of the undesirable off-flavor diacetyl. The postfermentation removal of diacetyl can notably limit the production rate of lager beer (Krogerus and Gibson 2013b). Diacetyl formation is coupled with valine biosynthesis during fermentation, and the amount of diacetyl formed is linked to the activity of the $I L V 2$ - and $I L V 6$-encoded acetohydroxyacid synthase enzyme and subunit. Recent studies have suggested a correlation between ILV6 expression and diacetyl production (Duong et al. 2011; Gibson et al. 2015), while the sequencing of several industrial lager yeasts revealed higher copy numbers of $I L V$ genes in strains producing more diacetyl (Van den Broek et al. 2015). The expression of ILV2 and ILV6 genes was not monitored during this study, but the sequencing data suggest they were present in higher copy numbers in the allotriploid and allotetraploid hybrid strains (data not shown). Environmental factors also affect diacetyl formation and removal to a large extent. For example, a low wort $\mathrm{pH}$ increases $\alpha$-acetolactate decarboxylation and diacetyl removal rates, which here explain the more rapid diacetyl removal that was observed for the allodiploid Hybrid A2 compared to the other hybrid strains (Krogerus et al. 2015b).

The variation that was observed between the hybrid strains in fermentation characteristics and aroma profiles highlights several benefits and drawbacks of both the hybrid generation methods, rare mating and spore mating. The hybrids produced through rare mating, Hybrid C4 and Hybrid B3, outperformed the parent strains and the allodiploid Hybrid A2 during fermentation and, in the case of the allotetraploid Hybrid C4, produced beer with the highest concentration of flavor-active esters. While they also showed higher ethanol tolerances, they had lower viabilities after fermentation. It has also been shown that the genetic stability of hybrids produced with rare mating is lower than that of spore-to-spore hybrids (Pérez-Través et al. 2012; Kunicka-Styczynska and Rajkowska 2011), which here was evident by the apparent chromosome losses in the allotetraploid Hybrid C4 (a loss of one S. eubayanus-derived chromosome X). Hybrids B3 and C4 also contained only a single copy of the $S$. cerevisiae-derived chromosome III, containing the mating type locus. However, it is likely that this loss occurred prior to the hybridization, and this loss of heterozygosity allowed rare mating to occur (Hiraoka et al. 2000). Similar losses of chromosome III can also be observed in industrial lager strains (Walther et al. 2014; Van den Broek et al. 2015). Genetic instability could be exploited for further strain development through adaptive evolution, as it was recently shown that polyploid yeast undergo faster adaptation (Selmecki et al. 2015). Further research should be carried out in order to investigate the long-term stability of these hybrids strains, e.g., through serial repitching and the monitoring of genome stabilization and chromosomal rearrangements.

An aspect that considerably limits the applicability of sporeto-spore mating is the fact that sporulation is often poor in industrial brewing yeasts (Bilinski et al. 1986). However, it is expected that the diversity among hybrids generated by sporeto-spore mating should be greater than those generated through rare mating, as a result of meiotic recombination during spore formation (Marullo et al. 2004; Neiman 2011). This may result in the diploid hybrids losing phenotypic traits from the parent strains (Pérez-Través et al. 2015), as was observed here, e.g., for flocculation, where a much lower flocculation ability was observed for the allodiploid Hybrid A2 compared to the Hybrid B3 and Hybrid C4. However, this can also be used beneficially to eliminate unwanted phenotypic traits, such as excessive flocculation and production of phenolic off-flavors (Russell et al. 1983). This is relevant to the present study as well since a clear phenolic clove-like aroma, caused by the presence of 4vinylguaiacol (Coghe et al. 2004), was detected in all the beers. This aroma is typically unwanted in lager beer, and therefore future attempts should be made to remove this characteristic and increase the industrial applicability of these new hybrid lager strains. As allodiploid hybrids produced by spore-tospore mating are susceptible to genetic segregation through meiosis, especially where crosses involve heterozygous parent strains, future studies could assess genetic and phenotypic variation that exists among such hybrids. Homozygous parent strains could be created to reduce the effect of recombination and could act as control strains in such studies.

In conclusion, the results of this study show that interspecific hybridization is a useful non-GM tool for improving and 
developing brewing yeast, and that the physiological properties of these newly generated hybrids can be controlled to some extent through their ploidy and subgenome inheritance. The hybrids not only outperformed the parent strains in relation to fermentation rate but also produced beer with higher concentrations of certain flavor-active esters. Transcriptional analysis revealed that the increased formation of esters in the hybrid strains could be partly explained by the combined, and sometimes even increased, gene transcription levels of orthologous genes inherited from both parent strains. Further research combining interspecific hybridization and adaptive evolution could yield additional powerful tools for the creation of bespoke lager yeast.

Acknowledgments We thank Annika Wilhelmson for her support throughout, Eero Mattila for wort preparation and other assistance in the VTT Pilot Brewery, and Aila Siltala for skilled technical assistance. Research at VTT was supported by the Alfred Kordelin Foundation, Svenska Kulturfonden-The Swedish Cultural Foundation in Finland, PBL Brewing Laboratory, the Academy of Finland (Academy Project 276480), and the European Union's Seventh Framework Programme FP7/2007-2013/ under REA grant agreement no. 606795. Research in GL lab is supported by ATIP-Avenir (CNRS/INSERM), ARC (grant no. PJA 20151203273), FP7-PEOPLE-2012-CIG (grant no. 322035), the French National Research Agency (grant nos. ANR-13-BSV60006-01 and 11-LABX-0028-01), Cancéropôle PACA (AAP émergence 2015), and DuPont Young Professor Award. JXY is supported by a post-doctoral fellowship from ARC (PDF20150602803).

Compliance with ethical standards This article does not contain any studies with human participants or animals performed by any of the authors.

Conflict of interest The authors declare that they have no competing interests.

Open Access This article is distributed under the terms of the Creative Commons Attribution 4.0 International License (http:// creativecommons.org/licenses/by/4.0/), which permits unrestricted use, distribution, and reproduction in any medium, provided you give appropriate credit to the original author(s) and the source, provide a link to the Creative Commons license, and indicate if changes were made.

\section{References}

Abyzov A, Urban A, Snyder M, Gerstein M (2011) CNVnator: an approach to discover, genotype, and characterize typical and atypical $\mathrm{CNV}$ from family and population genome sequencing. Genome Res 21:974-984

Aquilani B, Laureti T, Poponi S, Secondi L (2015) Beer choice and consumption determinants when craft beers are tasted: an exploratory study of consumer preferences. Food Qual Prefer 41:214-224

Baker E, Wang B, Bellora N, Peris D, Hulfachor A, Koshalek J, Adams M, Libkind D, Hittinger C (2015) The genome sequence of Saccharomyces eubayanus and the domestication of lager-brewing yeasts. Mol Biol Evol 32:2818-2831

Bandara A, Fraser S, Chambers P, Stanley G (2009) Trehalose promotes the survival of Saccharomyces cerevisiae during lethal ethanol stress, but does not influence growth under sublethal ethanol stress. FEMS Yeast Res 9:1208-1216

Bellon J, Eglinton J, Siebert T, Pollnitz A, Rose L, de Barros LM, Chambers P (2011) Newly generated interspecific wine yeast hybrids introduce flavour and aroma diversity to wines. Appl Microbiol Biotechnol 91:603-612

Bellon J, Schmid F, Capone D, Dunn B, Chambers P (2013) Introducing a new breed of wine yeast: interspecific hybridisation between a commercial Saccharomyces cerevisiae wine yeast and Saccharomyces mikatae. PLoS ONE 8:e62053. doi:10.1371/journal.pone.0062053

Bilinski C, Russell I, Stewart G (1986) Analysis of sporulation in brewer's yeast: induction of tetrad formation. J Inst Brew 92:594 598

Blieck L, Toye G, Dumortier F, Verstrepen K, Delvaux F, Thevelein J, Van Dijck P (2007) Isolation and characterization of brewer's yeast variants with improved fermentation performance under highgravity conditions. Appl Environ Microbiol 73:815-824

Boeke J, Trueheart J, Natsoulis G, Fink G (1987) 5-Fluoroorotic acid as a selective agent in yeast molecular genetics. Methods Enzymol 154: 164-175

Boetzer M, Pirovana W (2012) Toward almost closed genomes with GapFiller. Genome Biol 13:R56. doi:10.1186/gb-2012-13-6-r56

Boetzer M, Pirovano W (2014) SSPACE-LongRead: scaffolding bacterial draft genomes using long read sequence information. BMC Bioinf 15:211. doi:10.1186/1471-2105-15-211

Bolat I, Romagnoli G, Zhu F, Pronk J, Daran J (2013) Functional analysis and transcriptional regulation of two orthologs of $A R O 10$, encoding broad-substrate-specificity 2-oxo-acid decarboxylases, in the brewing yeast Saccharomyces pastorianus CBS1483. FEMS Yeast Res 13:505-517

Cebollero E, Gonzalez-Ramos D, Tabera L, Gonzalez R (2007) Transgenic wine yeast technology comes of age: is it time for transgenic wine? Biotechnol Lett 29:191-200

Chaisson M, Tesler G (2012) Mapping single molecule sequencing reads using basic local alignment with successive refinement (BLASR): application and theory. BMC Bioinf 13:238. doi:10.1186/14712105-13-238

Chen Z (2007) Genetic and epigenetic mechanisms for gene expression and phenotypic variation in plant polyploids. Annu Rev Plant Biol 58:377-406

Chen Z (2013) Genomic and epigenetic insights into the molecular bases of heterosis. Nat Rev Genet 14:471-482

Chiang C, Layer R, Faust G, Lindberg M, Rose D, Garrison E, Marth G, Quinlan A, Hall I (2015) SpeedSeq: ultra-fast personal genome analysis and interpretation. Nat Methods 12:966-968

Coghe S, Benoot K, Delvaux F, Vanderhaegen B, Delvaux FR (2004) Ferulic acid release and 4-vinylguaiacol formation during brewing and fermentation: indication for feruloyl esterase activity in Saccharomyces cerevisiae. J Agric Food Chem 52:602-608

Cousseau F, Alves S Jr, Trichez D, Stambuk B (2013) Characterization of maltotriose transporters from the Saccharomyces eubayanus subgenome of the hybrid Saccharomyces pastorianus lager brewing yeast strain Weihenstephan 34/70. Lett Appl Microbiol 56:21-29

D'Hautcourt O, Smart K (1999) Measurement of brewing yeast flocculation. J Am Soc Brew Chem 57:123-128

da Silva T, Albertin W, Dillmann C, Bely M, la Guerche S, Giraud C, Huet S, Sicard D, Masneuf-Pomarede I, de Vienne D, Marullo P (2015) Hybridization within Saccharomyces genus results in homoeostasis and phenotypic novelty in winemaking conditions. PLoS ONE 10:e0123834. doi:10.1371/journal.pone.0123834

Dietvorst J, Londesborough J, Steensma HY (2005) Maltotriose utilization by lager yeast strains: MTT1 encodes a maltotriose transporter. Yeast 22:775-788

Dunn B, Sherlock G (2008) Reconstruction of the genome origins and evolution of the hybrid lager yeast Saccharomyces pastorianus. Genome Res 18:1610-1623 
Duong C, Strack L, Futschik M, Katou Y, Nakao Y, Fujimura T, Shirahige K, Kodama Y, Nevoigt E (2011) Identification of Sc-type ILV6 as a target to reduce diacetyl formation in lager brewers' yeast. Metab Eng 13:638-647

Engel S, Dietrich F, Fisk D, Binkley G, Balakrishnan R, Costanzo M, Dwight S, Hitz B, Karra K, Nash R, Weng S, Wong E, Lloyd P, Skrzypek M, Miyasato S, Simison M, Cherry J (2013) The reference genome sequence of Saccharomyces cerevisiae: then and now. G3 4: 389-398

European Brewery Convention (2004) Analytica-EBC. Verlag Hans Carl Getränke-Fachverlag, Nürnberg

Fu D, Xiao M, Hayward A, Jiang G, Zhu L, Zhou Q, Li J, Zhang M (2015) What is crop heterosis: new insights into an old topic. J Appl Genet 56:1-13

Gamero A, Tronchoni J, Querol A, Belloch C (2013) Production of aroma compounds by cryotolerant Saccharomyces species and hybrids at low and moderate fermentation temperatures. J Appl Microbiol 114: 1405-1414

Garcia Sanchez R, Solodovnikova N, Wendland J (2012) Breeding of lager yeast with Saccharomyces cerevisiae improves stress resistance and fermentation performance. Yeast 29:343-355

García-Alcalde F, Okonechnikov K, Carbonell J, Cruz L, Götz S, Tarazona S, Dopazo J, Meyer T, Conesa A (2012) Qualimap: evaluating next-generation sequencing alignment data. Bioinformatics 28:2678-2679

Garrison E, Marth G (2012) Haplotype-based variant detection from short-read sequencing. arXiv:1207.3907

Gibson B (2011) 125th anniversary review: improvement of higher gravity brewery fermentation via wort enrichment and supplementation. J Inst Brew 117:268-284

Gibson B, Liti G (2015) Saccharomyces pastorianus: genomic insights inspiring innovation for industry. Yeast 32:17-27

Gibson B, Lawrence S, Leclaire J, Powell C, Smart K (2007) Yeast responses to stresses associated with industrial brewery handling. FEMS Microbiol Rev 31:535-569

Gibson B, Storgårds E, Krogerus K, Vidgren V (2013a) Comparative physiology and fermentation performance of Saaz and Frohberg lager yeast strains and the parental species Saccharomyces eubayanus. Yeast 30:255-266

Gibson B, Londesborough J, Rautio K, Mattinen L, Vidgren V (2013b) Transcription of $\alpha$-glucoside transport and metabolism genes in the hybrid brewing yeast Saccharomyces pastorianus with respect to gene provenance and fermentation temperature. J Inst Brew 119: 23-31

Gibson B, Krogerus K, Ekberg J, Monroux A, Mattinen L, Rautio J, Vidgren V (2015) Variation in $\alpha$-acetolactate production within the hybrid lager yeast group Saccharomyces pastorianus and the affirmation of the central role of the ILV6 gene. Yeast 32:301-316

Gueldener U, Heinisch J, Koehler G, Voss D, Hegemann J (2002) A second set of loxP marker cassettes for Cre-mediated multiple gene knockouts in budding yeast. Nucleic Acids Res 30:e23

Guimarães P, Virtanen H, Londesborough J (2006) Direct evidence that maltose transport activity is affected by the lipid composition of brewer's yeast. J Inst Brew 112:203-209

Haas B, Salzberg S, Zhu W, Pertea M, Allen J, Orvis J, White O, Buell C, Wortman J (2008) Automated eukaryotic gene structure annotation using EVidenceModeler and the program to assemble spliced alignments. Genome Biol 9:R7. doi:10.1186/gb-2008-9-1-r7

Haase S, Reed S (2002) Improved flow cytometric analysis of the budding yeast cell cycle. Cell Cycle 1:132-136

He Y, Dong J, Yin H, Chen P, Lin H, Chen L (2014) Monitoring of the production of flavour compounds by analysis of the gene transcription involved in higher alcohol and ester formation by the brewer's yeast Saccharomyces pastorianus using a multiplex RT-qPCR assay. J Inst Brew 120:119-126
Hebly M, Brickwedde A, Bolat I, Driessen M, de Hulster E, van den Broek M, Pronk J, Geertman J, Daran J, Daran-Lapujade P (2015) $S$. cerevisiae $\times S$. eubayanus interspecific hybrid, best of both worlds and beyond. FEMS Yeast Res 15:fov005

Henderson C, Block D (2014) Examining the role of membrane lipid composition in determining the ethanol tolerance of Saccharomyces cerevisiae. Appl Environ Microbiol 80:2966-2972

Hiralal L, Olaniran A, Pillay B (2014) Aroma-active ester profile of ale beer produced under different fermentation and nutritional conditions. J Biosci Bioeng 117:57-64

Hiraoka M, Watanabe K, Umezu K, Maki H (2000) Spontaneous loss of heterozygosity in diploid Saccharomyces cerevisiae cells. Genetics 156:1531-1548

Holt C, Yandell M (2011) MAKER2: an annotation pipeline and genomedatabase management tool for second-generation genome projects. BMC Bioinf 12:491. doi:10.1186/1471-2105-12-491

Horinouchi T, Yoshikawa K, Kawaide R, Furusawa C, Nakao Y, Hirasawa T, Shimizu H (2010) Genome-wide expression analysis of Saccharomyces pastorianus orthologous genes using oligonucleotide microarrays. J Biosci Bioeng 110:602-607

Jiang H, Lei R, Ding S, Zhu S (2014) Skewer: a fast and accurate adapter trimmer for next-generation sequencing paired-end reads. BMC Bioinf 15:182. doi:10.1186/1471-2105-15-182

Klambauer G, Schwarzbauer K, Mayr A, Clevert D, Mitterecker A, Bodenhofer U, Hochreiter S (2012) Cn.MOPS: mixture of Poissons for discovering copy number variations in nextgeneration sequencing data with a low false discovery rate. Nucleic Acids Res 40:e69. doi:10.1093/nar/gks003

Kolmogorov M, Raney B, Paten B, Pham S (2014) Ragout — a referenceassisted assembly tool for bacterial genomes. Bioinformatics 30 : i302-i309. doi:10.1093/bioinformatics/btu280

Krogerus K, Gibson B (2013a) Influence of valine and other amino acids on total diacetyl and 2,3-pentanedione levels during fermentation of brewer's wort. Appl Microbiol Biotechnol 97:6919-6930

Krogerus K, Gibson B (2013b) 125th anniversary review: diacetyl and its control during brewery fermentation. J Inst Brew 119:86-97

Krogerus K, Magalhães F, Vidgren V, Gibson B (2015a) New lager yeast strains generated by interspecific hybridization. J Ind Microbiol Biotechnol 42:769-778

Krogerus K, Gibson B, Hytönen E (2015b) An improved model for prediction of wort fermentation progress and total diacetyl profile. J Am Soc Brew Chem 73:90-99

Kunicka-Styczynska A, Rajkowska K (2011) Physiological and genetic stability of hybrids of industrial wine yeasts Saccharomyces sensu stricto complex. J Appl Microbiol 110:1538-1549

Lawrence M, Huber W, Pagès H, Aboyoun O, Carlson M, Gentleman R, Morgan M, Carey V (2013) Software for computing and annotating genomic ranges. PLoS Comput Biol 9(8):e1003118. doi:10.1371/ journal.pcbi.1003118

Li H, Handsaker B, Wysoker A, Fennell T, Ruan J, Homer N, Marth G, Abecasis G, Durbin R, 1000 Genome Project Data Processing Subgroup (2009) The sequence alignment/map format and SAMtools. Bioinformatics 25:2078-2079

Li C, Tzeng J, Huang-Mo S (2012) Effects of cis and trans regulatory variations on the expression divergence of heat shock response genes between yeast strains. Gene 506:93-97

Libkind D, Hittinger C, Valerio E, Goncalves C, Dover J, Johnston M, Goncalves P, Sampaio J (2011) Microbe domestication and the identification of the wild genetic stock of lager-brewing yeast. Proc Natl Acad Sci U S A 108:14539-14544

Lilly M, Bauer F, Styger G, Lambrechts M, Pretorius I (2006) The effect of increased branched-chain amino acid transaminase activity in yeast on the production of higher alcohols and on the flavour profiles of wine and distillates. FEMS Yeast Res 6:726-743

Lippman Z, Zamir D (2007) Heterosis: revisiting the magic. Trends Genet 23:60-66 
Liti G, Peruffo A, James S, Roberts I, Louis E (2005) Inferences of evolutionary relationships from a population survey of LTRretrotransposons and telomeric-associated sequences in the Saccharomyces sensu stricto complex. Yeast 22:177-192

Marullo P, Bely M, Masneuf-Pomarede I, Aigle M, Dubourdieu D (2004) Inheritable nature of enological quantitative traits is demonstrated by meiotic segregation of industrial wine yeast strains. FEMS Yeast Res 4:711-719

Meilgaard M (1982) Prediction of flavor differences between beers from their chemical composition. J Agric Food Chem 30:1009-1017

Mertens S, Steensels J, Saels V, de Rouck G, Aerts G, Verstrepen K (2015) A large set of newly created interspecific yeast hybrids increases aromatic diversity in lager beers. Appl Environ Microbiol 81:8202-8214

Morgan M, Pagès H, Obenchain V, Hayden N (2010) Rsamtools: binary alignment (BAM), FASTA, variant call (BCF), and tabix file import. $\mathrm{R}$ package version 1.22.0, http://bioconductor.org/packages/release/ bioc/html/Rsamtools.html

Muir A, Harrison E, Wheals A (2011) A multiplex set of species-specific primers for rapid identification of members of the genus Saccharomyces. FEMS Yeast Res 11:552-563

Nakao Y, Kanamori T, Itoh T, Kodama Y, Rainieri S, Nakamura N, Shimonaga T, Hattori M, Ashikari T (2009) Genome sequence of the lager brewing yeast, an interspecies hybrid. DNA Res 16:115129

Neiman A (2011) Sporulation in the budding yeast Saccharomyces cerevisiae. Genetics 189:737-765

Otto T, Dillon G, Degrave W, Berriman M (2011) RATT: rapid annotation transfer tool. Nucleic Acids Res 39:e57. doi:10.1093/nar/gkq1268

Pengelly R, Wheals A (2013) Rapid identification of Saccharomyces eubayanus and its hybrids. FEMS Yeast Res 13:156-161

Pérez-Través L, Lopes C, Barrio E, Querol A (2012) Evaluation of different genetic procedures for the generation of artificial hybrids in Saccharomyces genus for winemaking. Int J Food Microbiol 156: 102-111

Pérez-Través L, Lopes C, González R, Barrio E, Querol A (2015) Physiological and genomic characterisation of Saccharomyces cerevisiae hybrids with improved fermentation performance and mannoprotein release capacity. Int J Food Microbiol 205:30-40

Pfaffl M (2001) A new mathematical model for relative quantification in real-time RT-PCR. Nucleic Acids Res 29:e45

Pham T, Wimalasena T, Box W, Koivuranta K, Storgårds E, Smart K, Gibson B (2011) Evaluation of ITS PCR and RFLP for differentiation and identification of brewing yeast and brewery 'wild' yeast contaminants. J Inst Brew 117:556-568

Pires E, Teixeira J, Branyik T, Vicente A (2014) Yeast: the soul of beer's aroma- a review of flavour-active esters and higher alcohols produced by the brewing yeast. Appl Microbiol Biotechnol 98:19371949

Plech M, de Visser J, Korona R (2014) Heterosis is prevalent among domesticated but not wild strains of Saccharomyces cerevisiae. G3 4:315-323

Procopio S, Brunner M, Becker T (2014) Differential transcribed yeast genes involved in flavour formation and its associated amino acid metabolism during brewery fermentation. Eur Food Res Technol 239:421-439

Proux-Wéra E, Armisén D, Byrne K, Wolfe K (2012) A pipeline for automated annotation of yeast genome sequences by a conserved-synteny approach. BMC Bioinf 13:237. doi:10.1186/1471-2105-13-237

Rautio J, Huuskonen A, Vuokko H, Vidgren V, Londesborough J (2007) Monitoring yeast physiology during very high gravity wort fermentations by frequent analysis of gene expression. Yeast 24:741-760

Russell I, Hancock I, Stewart G (1983) Construction of dextrin fermentative yeast strains that do not produce phenolic off-flavours in beer. J Am Soc Brew Chem 41:45-51
Sadeh A, Movshovich N, Volokh M, Gheber L, Aharoni A (2011) Finetuning of the Msn2/4-mediated yeast stress responses as revealed by systematic deletion of Msn2/4 partners. Mol Biol Cell 22:31273138

Saerens S, Verstrepen K, Van Laere S, Voet A, Van Dijck P, Delvaux FR, Thevelein J (2006) The Saccharomyces cerevisiae EHT1 and EEB1 genes encode novel enzymes with medium-chain fatty acid ethyl ester synthesis and hydrolysis capacity. J Biol Chem 281:44464456

Saerens S, Verbelen P, Vanbeneden N, Thevelein J, Delvaux FR (2008) Monitoring the influence of high-gravity brewing and fermentation temperature on flavour formation by analysis of gene expression levels in brewing yeast. Appl Microbiol Biotechnol 80:1039-1051

Sato M, Kishimoto M, Watari J, Takashio M (2002) Breeding of brewer's yeast by hybridization between a top-fermenting yeast Saccharomyces cerevisiae and a cryophilic yeast Saccharomyces bayanus. J Biosci Bioeng 93:509-511

Scannell D, Zill O, Rokas A, Payen C, Dunham M, Eisen M, Rine J, Johnston M, Hittinger C (2011) The awesome power of yeast evolutionary genetics: new genome sequences and strain resources for the Saccharomyces sensu stricto genus. G3 1:11-25

Schoenfelder K, Fox D (2015) The expanding implications of polyploidy. J Cell Biol 209:485-491

Selmecki A, Maruvka Y, Richmond P, Guillet M, Shoresh N, Sorenson A, De S, Kishony R, Michor F, Dowell R, Pellman D (2015) Polyploidy can drive rapid adaptation in yeast. Nature 519:349-352

Shapira R, Levy T, Shaked S, Fridman E, David L (2014) Extensive heterosis in growth of yeast hybrids is explained by a combination of genetic models. Heredity 113:316-326

Smukalla S, Caldara M, Pochet N, Beauvais A, Guadagnini S, Yan C, Vinces M, Jansen A, Prevost M, Latgé J, Fink G, Foster K, Verstrepen K (2008) FLOI is a variable green beard gene that drives biofilm-like cooperation in budding yeast. Cell 135:726-737

Snoek T, Picca Nicolino M, Van den Bremt S, Mertens S, Saels V, Verplaetse A, Steensels J, Verstrepen K (2015) Large-scale robotassisted genome shuffling yields industrial Saccharomyces cerevisiae yeasts with increased ethanol tolerance. Biotechnol Biofuels 8:32

Steensels J, Meersman E, Snoek T, Saels V, Verstrepen K (2014a) Largescale selection and breeding to generate industrial yeasts with superior aroma production. Appl Environ Microbiol 80:6965-6975

Steensels J, Snoek T, Meersman E, Picca Nicolino M, Voordeckers K, Verstrepen K (2014b) Improving industrial yeast strains: exploiting natural and artificial diversity. FEMS Microbiol Rev 38:947-995

Stewart G, Hill A, Russell I (2013) 125th anniversary review: developments in brewing and distilling yeast strains. J Inst Brew 119:202220

Storchova Z (2014) Ploidy changes and genome stability in yeast. Yeast $31: 421-430$

Stribny J, Gamero A, Pérez-Torrado R, Querol A (2015) Saccharomyces kudriavzevii and Saccharomyces uvarum differ from Saccharomyces cerevisiae during the production of aroma-active higher alcohols and acetate esters using their amino acidic precursors. Int J Food Microbiol 205:41-46

Tirosh I, Reikhav S, Levy A, Barkai N (2009) A yeast hybrid provides insight into the evolution of gene expression regulation. Science 324:659-662

Twardowski T, Malyska A (2015) Uninformed and disinformed society and the GMO market. Trends Biotechnol 33:1-3

Van den Broek M, Bolat I, Nijkamp J, Ramos E, Luttik M, Koopman F, Geertman J, de Ridder D, Pronk J, Daran J (2015) Chromosomal copy number variation in Saccharomyces pastorianus evidence for extensive genome dynamics in industrial lager brewing strains. Appl Environ Microbiol 81:6253-6267

Verstrepen K, Van Laere S, Vanderhaegen B, Derdelinckx G, Dufour J, Pretorius I, Winderickx J, Thevelein J, Delvaux FR (2003) 
Expression levels of the yeast alcohol acetyltransferase genes ATF1, $L g-A T F 1$, and $A T F 2$ control the formation of a broad range of volatile esters. Appl Environ Microbiol 69:5228-5237

Vidgren V, Ruohonen L, Londesborough J (2005) Characterization and functional analysis of the $M A L$ and $M P H$ loci for maltose utilization in some ale and lager yeast strains. Appl Environ Microbiol 71:7846-7857

Vidgren V, Huuskonen A, Virtanen H, Ruohonen L, Londesborough J (2009) Improved fermentation performance of a lager yeast after repair of its $A G T 1$ maltose and maltotriose transporter genes. Appl Environ Microbiol 75:2333-2345

Vidgren V, Multanen J, Ruohonen L, Londesborough J (2010) The temperature dependence of maltose transport in ale and lager strains of brewer's yeast. FEMS Yeast Res 10:402-411

Vidgren V, Viljanen K, Mattinen L, Rautio J, Londesborough J (2014) Three Agt1 transporters from brewer's yeasts exhibit different temperature dependencies for maltose transport over the range of brewery temperatures $\left(0-20^{\circ} \mathrm{C}\right)$. FEMS Yeast Res 14:601-613

Walther A, Hesselbart A, Wendland J (2014) Genome sequence of Saccharomyces carlsbergensis, the world's first pure culture lager yeast. G3 4:783-793
Yamada R, Tanaka T, Ogino C, Kondo A (2010) Gene copy number and polyploidy on products formation in yeast. Appl Microbiol Biotechnol 88:849-857

Yao H, Dogra Gray A, Auger D, Birchler J (2013) Genomic dosage effects on heterosis in triploid maize. Proc Natl Acad Sci U S A 110:2665-2669

Yoshioka K, Hashimoto N (1981) Ester formation by alcohol acetyltransferase from brewer's yeast. Agric Biol Chem 45: 2183-2190

Zaret K, Sherman F (1985) Alpha-aminoadipate as a primary nitrogen source for Saccharomyces cerevisiae mutants. J Bacteriol 162:579583

Zhang C, Liu Y, Qi Y, Zhang J, Dai L, Lin X, Ziao D (2013) Increased esters and decreased higher alcohols production by engineered brewer's yeast strains. Eur Food Res Technol 236: 1009-1014

Zheng D, Wu X, Tao X, Wang P, Li P, Chi X, Li Y, Yan Q, Zhao Y (2011) Screening and construction of Saccharomyces cerevisiae strains with improved multi-tolerance and bioethanol fermentation performance. Bioresour Technol 102:3020-3027 